\title{
Review Article \\ Bioavailability of Dietary Polyphenols and Gut Microbiota Metabolism: Antimicrobial Properties
}

\author{
Laura Marín, Elisa M. Miguélez, Claudio J. Villar, and Felipe Lombó \\ Research Unit "Biotechnology and Experimental Therapy Based in Nutraceuticals-BITTEN", Instituto Universitario de \\ Oncología del Principado de Asturias (IUOPA), Universidad de Oviedo, 33006 Oviedo, Spain
}

Correspondence should be addressed to Felipe Lombó; lombofelipe@uniovi.es

Received 9 July 2014; Revised 13 October 2014; Accepted 19 October 2014

Academic Editor: Clara G. de los Reyes-Gavilán

Copyright (C) 2015 Laura Marín et al. This is an open access article distributed under the Creative Commons Attribution License, which permits unrestricted use, distribution, and reproduction in any medium, provided the original work is properly cited.

Polyphenolic compounds are plant nutraceuticals showing a huge structural diversity, including chlorogenic acids, hydrolyzable tannins, and flavonoids (flavonols, flavanones, flavan-3-ols, anthocyanidins, isoflavones, and flavones). Most of them occur as glycosylated derivatives in plants and foods. In order to become bioactive at human body, these polyphenols must undergo diverse intestinal transformations, due to the action of digestive enzymes, but also by the action of microbiota metabolism. After elimination of sugar tailoring (generating the corresponding aglycons) and diverse hydroxyl moieties, as well as further backbone reorganizations, the final absorbed compounds enter the portal vein circulation towards liver (where other enzymatic transformations take place) and from there to other organs, including behind the digestive tract or via blood towards urine excretion. During this transit along diverse tissues and organs, they are able to carry out strong antiviral, antibacterial, and antiparasitic activities. This paper revises and discusses these antimicrobial activities of dietary polyphenols and their relevance for human health, shedding light on the importance of polyphenols structure recognition by specific enzymes produced by intestinal microbial taxa.

\section{Bioavailability of Dietary Polyphenols}

1.1. Structural Diversity. Flavonoids are very abundant $15 \mathrm{C}$ secondary metabolites in plants, containing two aromatic rings (connected by a heterocycle pyrone ring), which are tailored with diverse hydroxyl moieties. Some are produced at chloroplasts as defense against oxidative damage generated during photosynthesis [1]; others are produced at the sexual organs as defense against solar UV [2], at the root area as attractants for bacterial and fungal symbionts [3], or as defense against virus, bacteria, fungi, and herbivores [4].

All flavonoids derive from L-phenylalanine, due to diverse transformations taking place at the phenylpropanoid pathway. Initial common steps are conversion of L-Phe in cinnamic acid (by phenyl ammonia lyase (PAL)), its conversion in $p$-coumaric acid (by cinnamate-4-hydroxylase $(\mathrm{C} 4 \mathrm{H})$ ), and its transformation in $p$-coumaroyl-CoA (by 4coumaroyl-CoA ligase (4CL)) [5]. Both $p$-coumaric acid and
p-coumaroyl-CoA are building blocks for hydroxycinnamic acids and flavonoids, respectively (Figure 1) [5].

In flavonoid biosynthesis, one molecule of $p$-coumaroyl$\mathrm{CoA}$ and three molecules of malonyl-CoA are used by the chalcone synthase (CHS) in order to generate a bicyclic chalcone as naringenin chalcone (Figure 1) [4]. Chalcones are substrates for chalcone isomerase $(\mathrm{CHI})$, which carries out the B-ring closure at these compounds, rendering flavanones (as naringenin from citrus fruits) (Figure 2). All flavonoid subfamilies derive from these $15 \mathrm{C}$ flavanones (Figure 2 shows the atom numbering and ring denomination). Other phenylpropanoid enzymes will generate diverse final products as shown in Figure 2 [4]. Flavone synthase (FNS) will generate flavones (as apigenin from celery). Isoflavone synthase (IFS) will generate isoflavones (as genistein from soy). Flavanone-3-hydroxylase $(\mathrm{F} 3 \mathrm{H})$ will generate dihydroflavonols (as aromadendrin from pine trees). Flavonol synthase (FLS) will generate flavonols (as quercetin from 


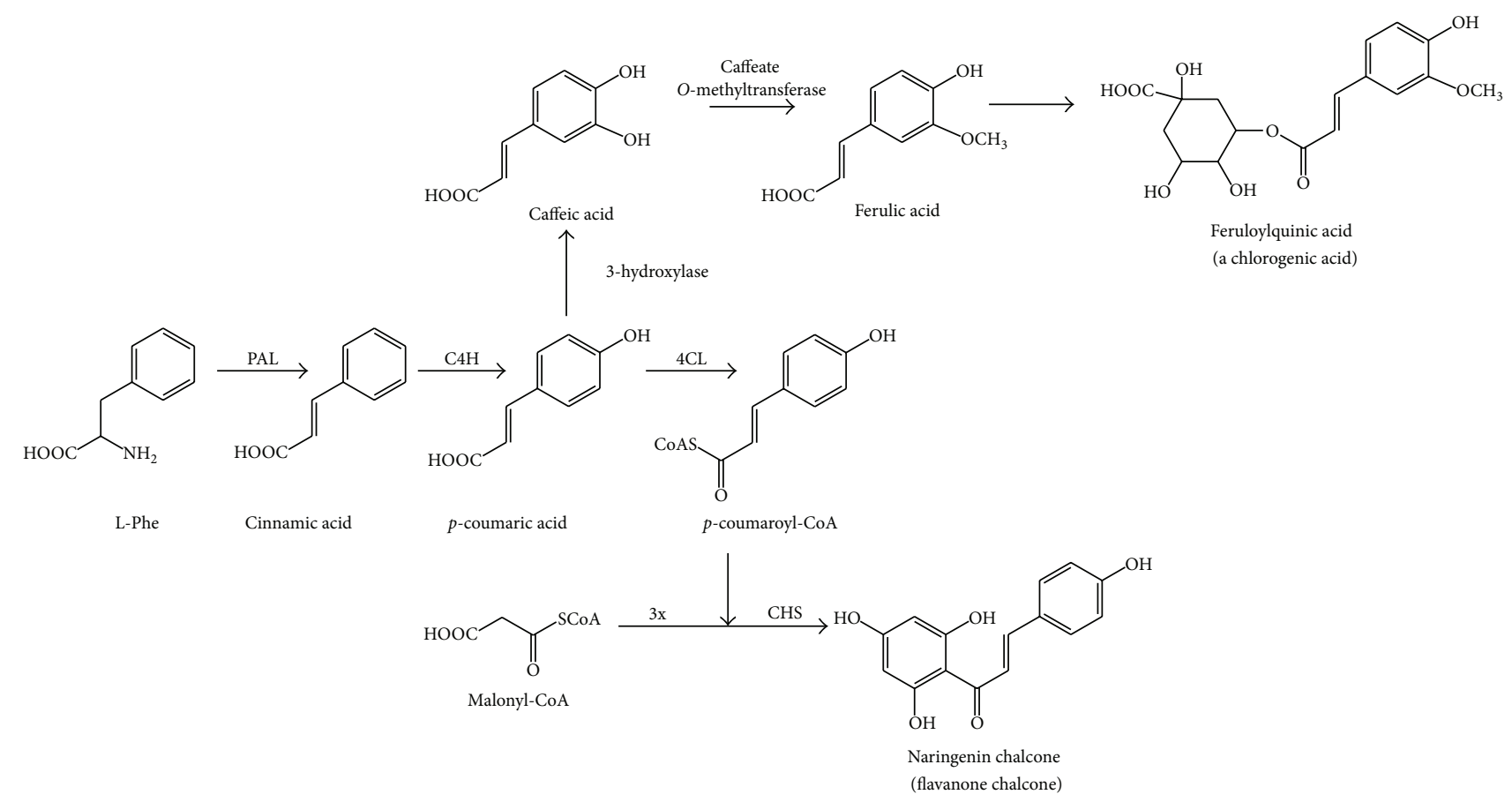

FIGURE 1: Initial common steps during hydroxycinnamic acids and flavonoids biosynthesis in plants.

onion or kaempferol from capers). Dihydroflavonol reductase (DFR) and anthocyanin synthase (ANS) will generate anthocyanidins (as pelargonidin from diverse red flowers). Anthocyanidin reductase (ANR) will generate flavan-3-ols (as epicatechin from cocoa).

Flavonoids are usually present and stored in plant tissues in the form of diverse derivatives, mostly as sugar O-conjugates at C2 (chalcones), at C3 (flavonols, anthocyanidins, and flavan-3-ols), or at C7 (flavanones, flavones, and isoflavones) positions. Most common bound sugars are glucose, galactose, rhamnose, xylose, rutinose, arabinopyranose, and arabinofuranose [6]. These modifications (and others as methylations and gallate tailoring) add extra structural stability to flavonoids during storage in vacuoles and chloroplasts [7-9]. Once the plant, fruit, or seed is recollected, flavonoids usually have good stability in this conjugated state and keep high concentrations in food and beverages. All these modifications in chemical structure and sugar binding will determine their absorption and bioavailability [10-13].

1.2. Intestinal Absorption. The study of flavonoids metabolism in human body is crucial to determine which ones are better absorbed and which ones lead to formation of bioactive metabolites. Following the ingestion of flavonoids, sugar moieties (as in quercetin-3-glucoside) are cleaved from the phenolic backbone in the small intestine and absorbed here. Enzymes as lactase phlorizin hydrolase (LPH) (at enterocyte membrane) or $\beta$-glucosidase (CBG) (cytosolic, for polar glycosides) hydrolyze glycosylated flavonoids and then aglycones enter epithelial cells by passive diffusion [1416] (Figure 3). However, flavonoids linked to a rhamnose moiety must reach the colon and be hydrolyzed by the $\alpha$ rhamnosidases secreted by the colon microbiota (as Bifidobacterium dentium), in order to proceed to its absorption [17] (Figure 3). Flavan-3-ols, such as (-)-epicatechin, are never glycosylated but often acylated by gallic acid. These compounds are absorbed at enterocyte level without any deconjugation or hydrolysis [18]. Proanthocyanidins are polymers of high molecular weight, and therefore oligomers larger than trimers are unlikely to be absorbed in the small intestine in their native form [19].

The other main family of polyphenols, hydroxycinnamic acids, are commonly esterified to sugars, organic acids, and lipids. There are no esterases in human tissues able to break these ester links, so the main site for its metabolism is colonic microbiota, although up to one third of their absorption can also take place in the small intestine [46-49]. Some hydroxycinnamic acids, as ellagitannins, are polymers (Figure 4). These are resistant to the action of LPH or CBG and consequently cannot be absorbed in the small intestine, reaching the colon, where its microbiota cleaves the conjugating moieties. The resultant aglycones are extensively metabolized by this microbiota, leading to the production of various hydroxyphenylacetic acids $[50,51]$.

Once a final derivative or aglycon has been absorbed (at small intestine or colon), it undergoes some degree of phase II metabolism at enterocyte level, as methylation (at $\mathrm{C}^{\prime}$ or $\mathrm{C}^{\prime}$ by catechol-O-methyltransferase (COMT)), sulfation (at $\mathrm{C}^{\prime}, \mathrm{C} 4{ }^{\prime}, \mathrm{C} 5$, or C7 by sulfotransferases (SULT)), and glucuronidation (by UDP-glucuronosyltransferases) (Figure 3). Then these products enter the blood stream by the portal vein, reaching the liver, where they may be subjected to more phase II metabolism, hence becoming conjugated and 


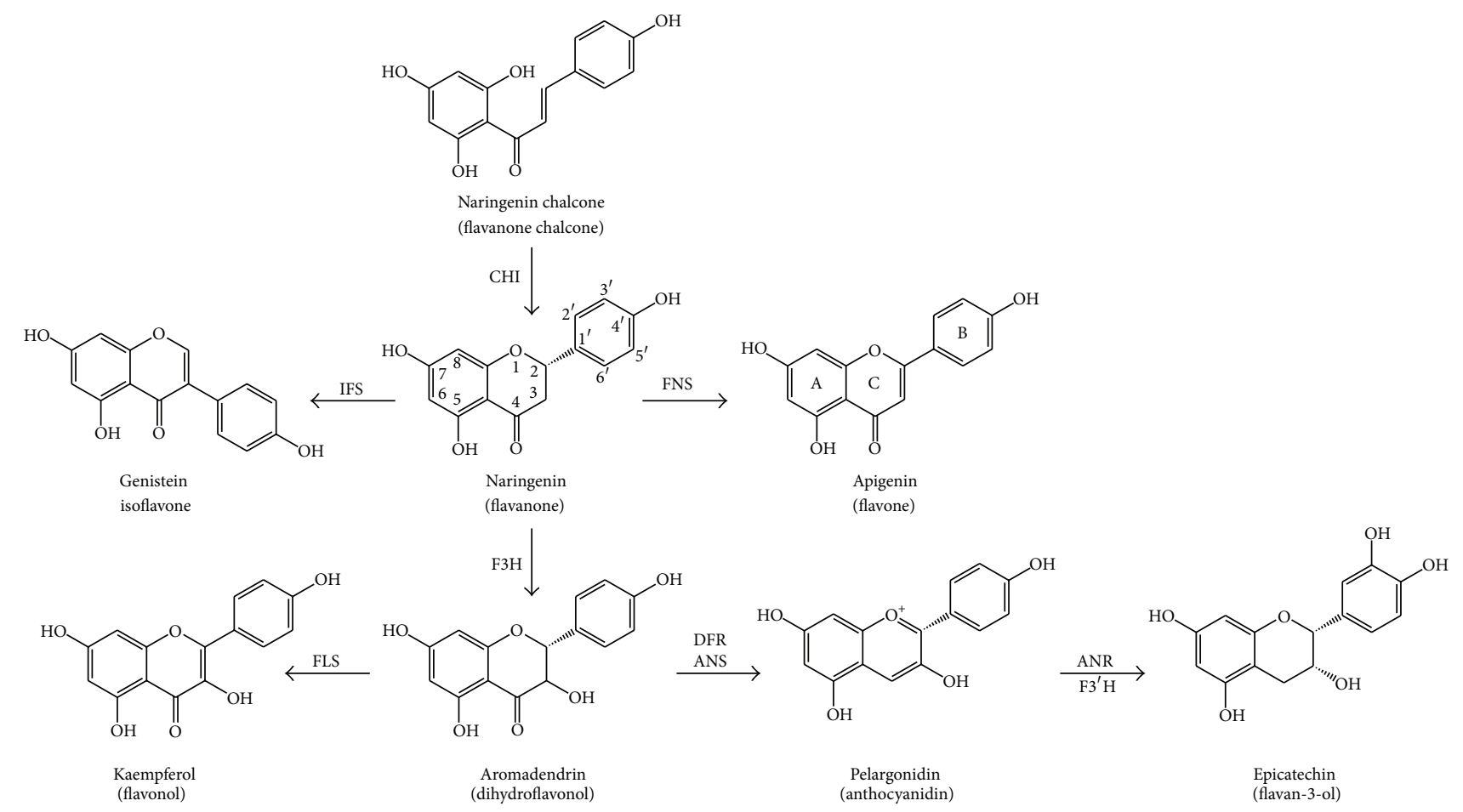

FIGURE 2: Biosynthetic steps for generation of flavonoid subfamilies. Naringenin structure shows atom numbering and apigenin structure shows rings denomination.

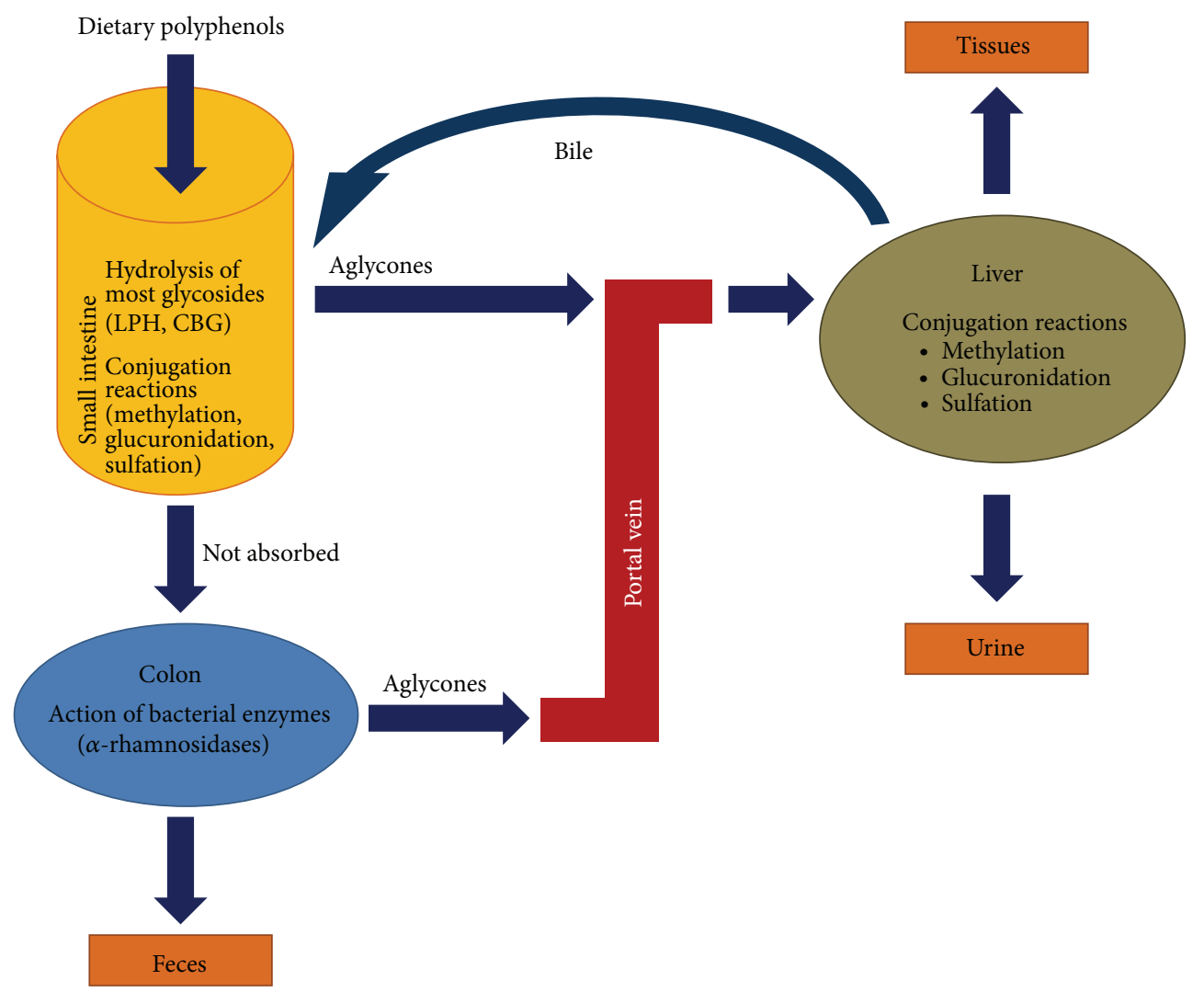

FIGURE 3: Absorption and metabolism routes for dietary polyphenols and their derivatives in humans. 


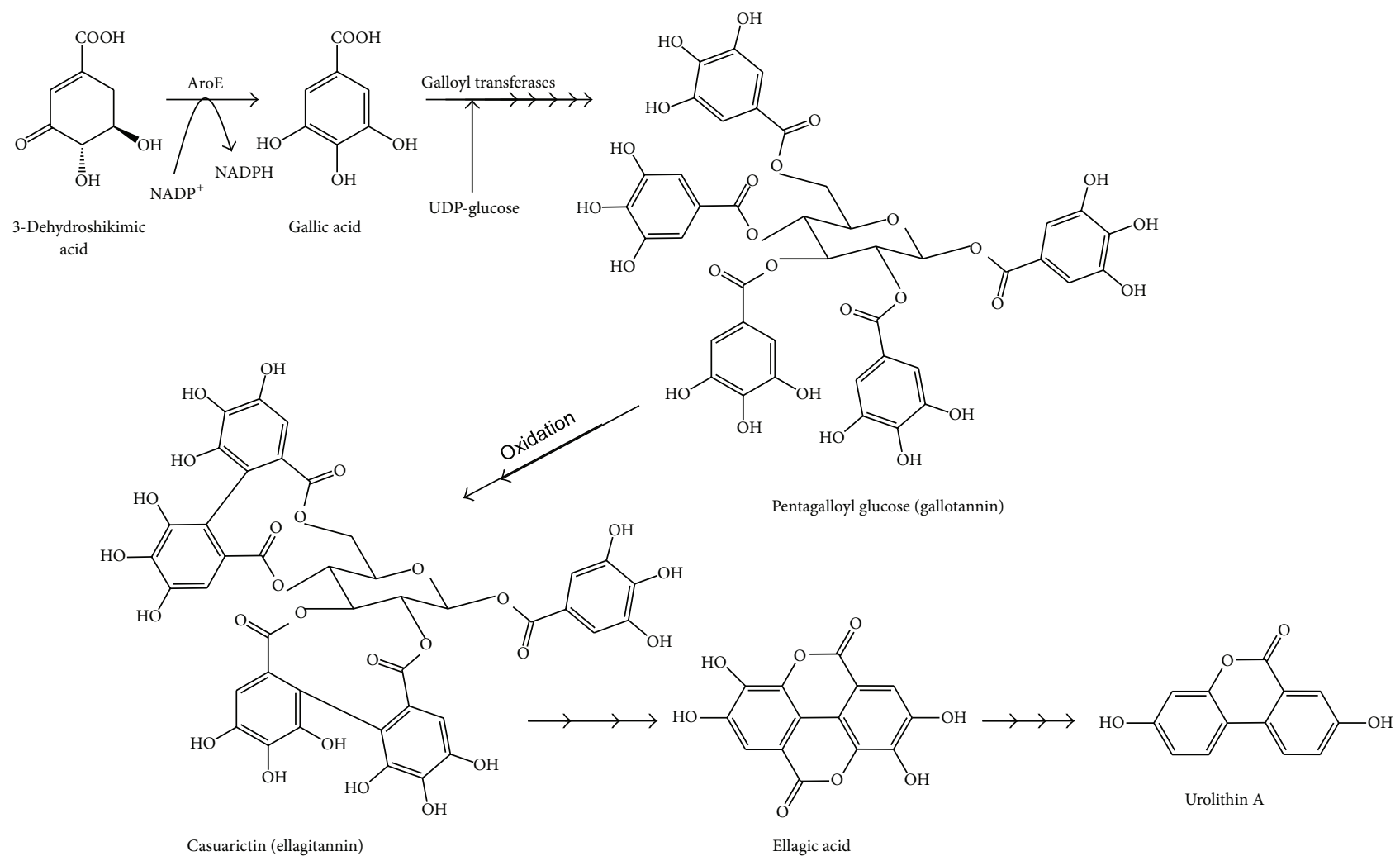

FIGURE 4: Biosynthetic steps for generation of two hydroxycinnamic acid polymers: ellagitannins and gallotannins.

transported to the bloodstream again until they are secreted in urine (Figure 3) [25, 52-61]. Some of the liver conjugates are then excreted as bile components back into the intestine (enterohepatic recirculation) and deconjugated compounds are regenerated by gut microbial enzymes before being reabsorbed again $[21,62,63]$. The unabsorbed metabolites are eliminated via faeces (Figure 3). All these conjugation mechanisms are highly efficient, and free aglycones are generally absent or present in low concentrations in plasma after nutritional doses. An exception is green tea catechins, whose aglycones constitute a significant proportion of the total amount in plasma, as they are nonglycosylated flavonoids in food and are readily absorbed at the small intestine without extra modifications [12].

\section{Antimicrobial Effects of Dietary Polyphenols and Their Gut Microbiota Metabolites}

The level of biotransformations suffered by a specific dietary polyphenol along the gastrointestinal tract is determined by two main factors. One is the specific structural subfamily of the polyphenol, as its scaffold will allow only some transformations, to be carried out by intestinal enzymes and gut microbiota species. This chemical structure will therefore, at this initial level, restrict the range of possible final bioactive products to be absorbed and consequently the scale of possible antimicrobial properties generated as a result of these biotransformations on dietary polyphenols. The second factor is the individual richness at the level of intestinal microbiota, as some specific biotransformations on dietary polyphenols can be carried out by a vast array of gut microbial species and genera (as deglycosylations), but other more specific chemical reactions on polyphenols require the presence of particular species or strains gifted with special genes coding for precise enzymes (as those responsible for intestinal generation of urolithins or $(S)$-equol).

Along the next sections, intestinal transformations of dietary polyphenols by diverse microbiota species (and the antimicrobial bioactivities of those derivatives) are organized according to their different structural subfamilies.

2.1. Flavonols. Flavonols (kaempferol, quercetin, and myricetin) (Figure 2) share the 3-hydroxyflavone backbone. Different positions for the phenolic $\mathrm{OH}$ moieties give diversity to this subgroup. They are found as glycosylates in many common foods as onion, capers, apples, broccoli, grapefruit, and plums. One of the most important diet flavonols is quercetin, whose $4^{\prime}$-O-glucoside and 3, $4^{\prime}$-O-diglucoside, among others, are abundant in onion and propolis, for example $[64,65]$.

The type of initial glycosylation pattern affects flavonols degradation rates in the gut. Metabolism of di- and trisaccharides is much slower compared to that of flavonol monosaccharides. Position of the hydroxyl groups may also influence their degradation, as recent studies indicate that flavonoids without hydroxyl groups at the $\mathrm{C} 5, \mathrm{C} 7$, and $\mathrm{C}^{\prime}{ }^{\prime}$ positions 
are degraded slower. Some gut microbiota species that have been involved in this hydrolysis are Bacteroides distasonis, Bacteroides uniformis, Bacteroides ovatus, Enterococcus casseliflavus, and Eubacterium ramulus [20, 21, 66, 67]. Also, the type of glycosidic bond (C- or O-glycosides) has influence on their degradation rates. Metabolism of a $C$-glycosidic bond seems to be much slower than the hydrolysis of an O-glycosidic bond. This is of interest from a nutraceutical point of view, as the slow degrading compounds may be more bioavailable, because they have greater opportunity to be absorbed than the ones that are degraded at a quicker rate at colon level [66].

Once flavonols have been metabolized in their aglycones, they are extensively degraded by other colonic microbiota, generating simpler phenolic compounds derived from Aand B-ring metabolism, after the flavonoid C-ring has been broken down [64] (Table 1, Figure 5). C-ring breakdown takes place at different positions (breaking the bond between $\mathrm{C} 1$ and $\mathrm{C} 2$ positions, between $\mathrm{C} 3$ and $\mathrm{C} 4$, or between $\mathrm{C} 4$ and $\mathrm{C10}$ ) giving rise to a high number of simple phenolics (Table 1, Figure 5). Some gut microbiota involved in this Cring breakdown is Eubacterium oxidoreducens, E. ramulus, E. casseliflavus, Clostridium orbiscidens, and others belonging to Butyrivibrio genus [20-23].

Following the C-ring fission, dehydroxylation occurs at the two remaining free phenolic rings (Figure 5). The hydroxylation pattern of A- and B-ring affects therefore the type of phenolic compounds produced, which will be finally absorbed at colon level. For example, the primary gut microbiota metabolites of quercetin are 2-(3,4-dihydroxyphenyl)-acetic acid (from A-ring) and protocatechuic acid (from B-ring), and those ones of myricetin are 2-(3,5dihydroxyphenyl)-acetic acid (from A-ring) and gallic acid (from B-ring) (Figure 5). Further dehydroxylation results in the formation of 2-(3-hydroxyphenyl)-acetic acid from both metabolites [22, 23, 68].

With respect to bioactivity, flavonols have been described as antiviral, inhibiting HIV-1 integrase, although in a nonspecific way, but also against HSV, respiratory syncytial virus, and poliovirus $[69,70]$. Quercetin has been shown to potentiate the action of acyclovir against HSV infection [71]. With respect to its antibacterial activity, oral administration of quercetin protected against Shigella infection in an animal model using a $140 \mathrm{mg} / \mathrm{kg}$ doses [72]. Escherichia coli gyrase is inhibited by quercetin and other flavonols, by inhibiting the ATPase GyrB subunit [73]. In in vitro assays, quercetin increases the bacterial cell membrane, giving rise to dissipation in membrane potential, and diminished cell motility, which is an important factor in bacterial virulence [74].

2.2. Flavanones. This class of flavonoids (hesperetin, naringenin) (Figure 2) has a 2,3-dihydro-2-phenylchromen-4-one structure. They are very abundant in citrus fruits and tomatoes. They seem to be more bioavailable than other close flavonoids such as flavonols or flavan-3-ols. This can be due to the fact that these compounds are less degraded by colonic microbiota and therefore they are more available for absorption [24]. The reason for this can be their common presence in food as rutinosides (bound to the disaccharide rutinose: 6-O$\alpha$-L-rhamnosyl-D-glucose) and neohesperidosides (bound to the disaccharide neohesperidose: $2-\mathrm{O}-\alpha$-L-rhamnosyl-Dglucose), a tailoring that seems to be resistant to some colon microbiota species. In both cases, these disaccharides are attached at position C7. By contrast, flavanone glucosides are rare.

Flavanones deglycosylation and further degradation by colonic microbiota pathway is similar to that observed in flavonols (Figure 5), with the main difference being C-ring cleavage between $\mathrm{C} 1$ and $\mathrm{C} 2$ positions or between $\mathrm{C} 4$ and $\mathrm{C} 10$ ones. Clostridium species and E. ramulus are able to carry out these transformations in the colon $[21,24]$.

The flavanone hesperetin aglycon (e.g., from citrus fruits) shows a notable inhibitory activity against vancomycinintermediate Staphylococcus aureus (VISA) and against Helicobacter pylori $[75,76]$. It possesses also a synergistic effect on VISA when combined with antibiotics like vancomycin and oxacillin [75]. It inhibits also intracellular replication of diverse virus (herpes simplex virus type-1, poliovirus type-1, parainfluenza virus type- 3 , influenza A virus, and respiratory syncytial virus) $[77,78]$.

Its glycosylated flavanone, hesperidin, shows antibacterial activity against Aeromonas hydrophila, an emerging human pathogen that causes both intestinal and extraintestinal infections. In a murine model, hesperidin showed inhibition of bacterial colonization and a significant increase in antiLPS IgM levels and reduction of anti-LPS and anti-ECP IgA levels to their normal values [79]. Hesperidin also shows activity against infection with human rotavirus [80] and against influenza virus replication in vitro by inhibition of the viral sialidase activity [81]. Growth of fungus Phytophthora citrophthora has been inhibited in vitro with this glycosylated flavanone, suggesting its role as antifungal toxin in the fruits of Citrus sinensis, a big source of this flavanone [82]. Also antiparasitic activity of hesperidin in vitro and in vivo has been shown against adult worms of Schistosoma mansoni, the causative agent of schistosomiasis [83].

Sulphonated hesperidin, one of its plasma metabolites, inhibits pathogens like Chlamydia trachomatis and Neisseria gonorrhoeae in vitro [84]. This conjugate also inhibits the enveloped viruses herpes simplex virus type-2 and human immunodeficiency virus (HIV) to the point that it has been suggested as a contraceptive antimicrobial agent against HIV transmission [84].

2.3. Flavan-3-Ols. Flavan-3-ols (Figure 2) form a very complex group of flavonoids consisting of simple flavan-3-ols (catechin and epicatechin; gallocatechin, epigallocatechin, and the corresponding gallate esters) and their polymeric forms. They are abundant in green tea, cocoa, kola, banana, and pomegranate.

Such broad polymerization degree and galloylation determine their bioavailability, as oligomers with a degree of polymerization $>3$ are not absorbed in the small intestine, and therefore they are metabolized in the colon $[19,25]$. Their gallate esters are catabolised by colon microbiota, as, for example, epicatechin gallate and epigallocatechin gallate, 
TABLE 1: Main metabolites derived from flavonoids and identified bacteria involved in their transformation.

\begin{tabular}{|c|c|c|c|c|}
\hline \multicolumn{2}{|c|}{ Precursors } & Main metabolites identified & Bacteria & References \\
\hline \multirow{3}{*}{ Flavonols } & Kaempferol & 2-(4-Hydroxyphenyl)propionic acid & Clostridium orbiscidens & {$[20]$} \\
\hline & Quercetin & $\begin{array}{l}\text { 2-(3,4-Dihydroxyphenyl)acetic acid } \\
\text { 2-(3-Hydroxyphenyl)acetic acid } \\
\text { 3-(3,4-Dihydroxyphenyl)propionic acid } \\
\text { 3-(3-Hydroxyphenyl)propionic acid }\end{array}$ & $\begin{array}{l}\text { C. orbiscidens, Eubacterium } \\
\text { oxidoreducens } \\
\text { Eubacterium ramulus } \\
\text { Enterococcus casseliflavus }\end{array}$ & {$[21-23]$} \\
\hline & Myricetin & $\begin{array}{l}\text { 2-(3,5-Dihydroxyphenyl)acetic acid } \\
\text { 2-(3-Hydroxyphenyl)acetic acid }\end{array}$ & C. orbiscidens, E. oxidoreducens & {$[20,22,23]$} \\
\hline Flavanones & Naringenin & 3-(4-Hydroxyphenyl)propionic acid & $\begin{array}{l}\text { Clostridium strains } \\
\text { E. ramulus }\end{array}$ & {$[21,24]$} \\
\hline \multirow[t]{2}{*}{ Flavan-3-ols } & $\begin{array}{l}\text { Catechin } \\
\text { Epicatechin }\end{array}$ & $\begin{array}{l}\text { 3-(3-Hydroxyphenyl)propionic acid } \\
\text { 5-(3', } \text { (4 }^{\prime} \text {-Dihydroxyphenyl)- } \gamma \text {-valerolactone } \\
\text { 5-(3,4-Dihydroxyphenyl)valeric acid } \\
\text { 3-(3,4-Dihydroxyphenyl)propionic acid }\end{array}$ & $\begin{array}{l}\text { Clostridium coccoides, Bifidobacterium } \\
\text { spp. }\end{array}$ & {$[25-28]$} \\
\hline & Epigallocatechin & $\begin{array}{l}\text { 5- }\left(3^{\prime}, 4^{\prime} \text {-Dihydroxyphenyl }\right)-\gamma \text {-valerolactone } \\
\text { 5-(3',5'-Dihydroxyphenyl)- } \gamma \text {-valerolactone }\end{array}$ & & \\
\hline \multirow{4}{*}{ Anthocyanins } & Cyanidin & 3,4-Dihydroxybenzoic acid & & \\
\hline & Peonidin & 3-Methoxy4-hydroxybenzoic acid & $\begin{array}{l}\text { Lactobacillus plantarum, Lactobacillus } \\
\text { casei, Lactobacillus acidophilus LA-5, }\end{array}$ & {$[29,30]$} \\
\hline & Pelargonidin & 4-Hydroxybenzoic acid & Bifidobacterium lactis BB-12 & \\
\hline & Malvidin & 3,4-Dimethoxybenzoic acid & & \\
\hline \multirow[t]{5}{*}{ Isoflavones } & Daidzein & $(S)$-Equol & $\begin{array}{l}\text { Bacteroides ovatus, Streptococcus } \\
\text { intermedius, Ruminococcus productus, } \\
\text { Eggerthella sp.Julong } 732 \text {, Enterococcus } \\
\text { faecium EPI1, Lactobacillus mucosae EPI2, } \\
\text { Finegoldia magna EPI3 }\end{array}$ & {$[31-33]$} \\
\hline & & O-Demethylangolensin & Clostridium spp. HGHA136 & {$[34]$} \\
\hline & Genistein & $6^{\prime}$-Hydroxy-O-desmethylangolensin & & [35] \\
\hline & Formononetin & Daidzein & & {$[36]$} \\
\hline & Biochanin A & Genistein & & {$[36]$} \\
\hline Flavones & $\begin{array}{l}\text { Luteolin, } \\
\text { apigenin }\end{array}$ & $\begin{array}{l}\text { 3-(3,4-Dihydroxyphenyl)-propionic acid, } \\
\text { 3-(4-hydroxyphenyl)-propionic acid, } \\
\text { 3-(3-hydroxyphenyl)-propionic acid, and } \\
\text { 4-hydroxycinnamic acid, phloretin }\end{array}$ & C. orbiscindens, Enterococcus avium & [37] \\
\hline
\end{tabular}<smiles>COc1cc(-c2oc3cc(O)cc(O)c3c(=O)c2OC)ccc1O</smiles>

FIGURE 5: Colonic degradation of quercetin glycosides, as an example of flavonol glycosides.

generating aglycones and gallate, which is further decarboxylated into pyrogallol $[25,26,85]$.

Flavan-3-ols aglycones lack a carbonyl group at C4 (as present in flavonols and flavanones). This may be the reason to avoid its transformation by colonic microbiota which modifies other types of flavonoids, as E. ramulus [27].

Once the initial gallate esters have been metabolized, the aglycones suffer C-ring opening, giving rise to 
diphenylpropan-2-diol, which is further converted into 5$\left(3^{\prime}, 4^{\prime}\right.$-dihydroxyphenyl)- $\gamma$-valerolactone. This lactone ring opens and gives rise to 5-(3,4-dihydroxyphenyl)valeric acid. Further transformations generate $\mathrm{OH}$-phenylpropionic and hydroxy-benzoic acids [25, 27] (Figure 6) (Table 1). Bacteria responsible for these metabolic reactions belong to the genera Bifidobacterium (as Bifidobacterium infantis) and Clostridium (as Clostridium coccoides). Actually, colonic populations of Bifidobacterium are increased in subjects consuming high doses of flavan-3-ols [28], which further enhance the benefits of flavan-3-ols consumption. These bacteria are resistant to these compounds because they do not use heme-containing enzymes, and these flavan-3-ols are important iron-chelating compounds [86].

In recent years, several studies have reported that the main catechin of green tea leaves, epigallocatechin-3-gallate (EGCG), has anti-infective properties [87]. Inhibition effect of EGCG on the capacity to infect cells by several viruses has been reported by different authors, who found that EGCG inhibits entry of hepatitis $C$ virus by impairing virus binding to the cell surface [88-90]. EGCG also shows antiviral effects against HIV-1, interfering with several aspects of its life cycle. It interacts with the viral envelope destroying viral particles [91], prevents attachment of virions to cells downregulating CD4 cell surface receptor expression [92, 93], affects viral replication via inhibition of reverse transcription [94], and inhibits proviral genome integration by binding between the integrase and the viral DNA [95]. The antiviral activity of EGCG against influenza virus infection in cell culture was attributed to agglutination of virus particles thus preventing virus from adsorbing to cells [96]. EGCG also inhibits the acidification of endosomes and lysosomes required for the fusion of viral and cellular membranes [97] as well as of neuraminidase activity responsible for preventing selfaggregation of virus particles [98]. Clinical studies performed to investigate the preventive effect of catechins consumption on influenza infection in humans found this statistically significant [99, 100]. Enterovirus 71 [101], human hepatitis $B$ virus [102], adenovirus [103], Epstein-Barr virus [104], and herpes simplex virus [105] are also clearly affected by EGCG.

With regard to antibacterial activity, there are multiple mechanisms by which EGCG exerts this activity against Staphylococcus, including damage to the lipid bilayer of the cell membrane [106], decrease slime production and inhibition of biofilm formation [107], binding and neutralization of enterotoxin B [108], and working with a synergistic effect in combination with $\beta$-lactams [109] or carbapenems [110]. Other bacteria killed by the action of EGCG are Streptococcus pyogenes [111], Bacillus spp. and Clostridium spp. [112], Salmonella typhi [113], and enterohemorrhagic E. coli [114]. The general antibacterial property of flavan-3-ols explaining these effects can be their chelating properties on iron, an important oligoelement for heme-utilizing bacteria [25]. EGCG inhibits growth of Legionella pneumophila inside macrophages not by any direct antibacterial effect on the pathogen, but due to selective changes in the immune response of macrophages and enhanced production of cytokines [115].
The antimicrobial effect of EGCG is also extended to eukaryote microorganisms, as against Candida spp. and the dermatophytes Cryptococcus neoformans and Trichophyton mentagrophytes [116]. EGCG specifically inhibits the germination of T. mentagrophytes conidia and subsequent hyphal growth [117]. These positive led to establishing in vivo research with EGCG in a murine model of disseminated candidiasis, showing its antifungal activity in vivo and its synergistic effect when combined with amphotericin B [118].

EGCG inhibits epimastigotes growth of Trypanosoma cruzi and increases mice survival rates in EGCG-treated animals that point out to a potential new compound for chemotherapy of Chagas disease [119]. EGCG also inhibits $37 \%-80 \%$ of binding of various isolates of Plasmodium falciparum to the ICAM-1 cellular receptor related to cerebral malaria [120]. The lethal mitochondrial damage that EGCG causes to Leishmania donovani [121] and Leishmania amazonensis [122] has been explained by its inhibition in the enzymatic activity of the parasite arginases [123].

2.4. Anthocyanidins. Unlike other flavonoids that are absorbed and secreted, anthocyanins, the glycosylated versions of anthocyanidin aglycons (as cyanidin, pelargonidin, and malvidin), do not appear to undergo extensive metabolism of the parent glycosides to glucuronic, sulfo or methyl derivatives, and therefore their bioavailability is very low [24]. Procyanidins occur in monomeric as well as in oligomeric and polymeric forms and are the most abundant and bioactive dietary polyphenols, as they are responsible for most red, blue, and purple color in fruits (specially berries), flowers, and leaves, besides having an important antioxidant activity $[29,30]$.

Since only a small part of ingested anthocyanins is absorbed at small intestine, large amounts of these compounds are likely to enter the colon, where they are deglycosylated by gut microbiota [124]. The gut microbiota has a high hydrolytic potential and ring scission properties so several anthocyanins degradation products have been identified. Some of them include vanillic, phloroglucinol, and protocatechuic acid $[124,125]$. For example, incubation of malvidin-3-glucoside (from grape extracts) with fecal bacteria results in formation of gallic, syringic, and $p$-coumaric acids (Figure 7) (Table 1). Some species responsible for this degradation are Lactobacillus plantarum, Lactobacillus casei, Lactobacillus acidophilus, and Bifidobacterium lactis [29, 30]. All the anthocyanins and their metabolites tested significantly enhance growth of Bifidobacterium spp., Lactobacillus spp., and Enterococcus spp. Therefore anthocyanins and their metabolites could perform a positive modulation of intestinal bacterial populations [126].

There are different mechanisms that can explain the antimicrobial activity of anthocyanins, as they can cause localized disintegration of bacterial outer membrane, leaking of cytoplasm (with the presence of significant amounts of cytoplasmic material and membrane debris outside the cells), and irregular shape [127]. The mechanisms thought to be responsible for the toxicity of pure anthocyanidin compounds to microorganisms include enzyme inhibition 

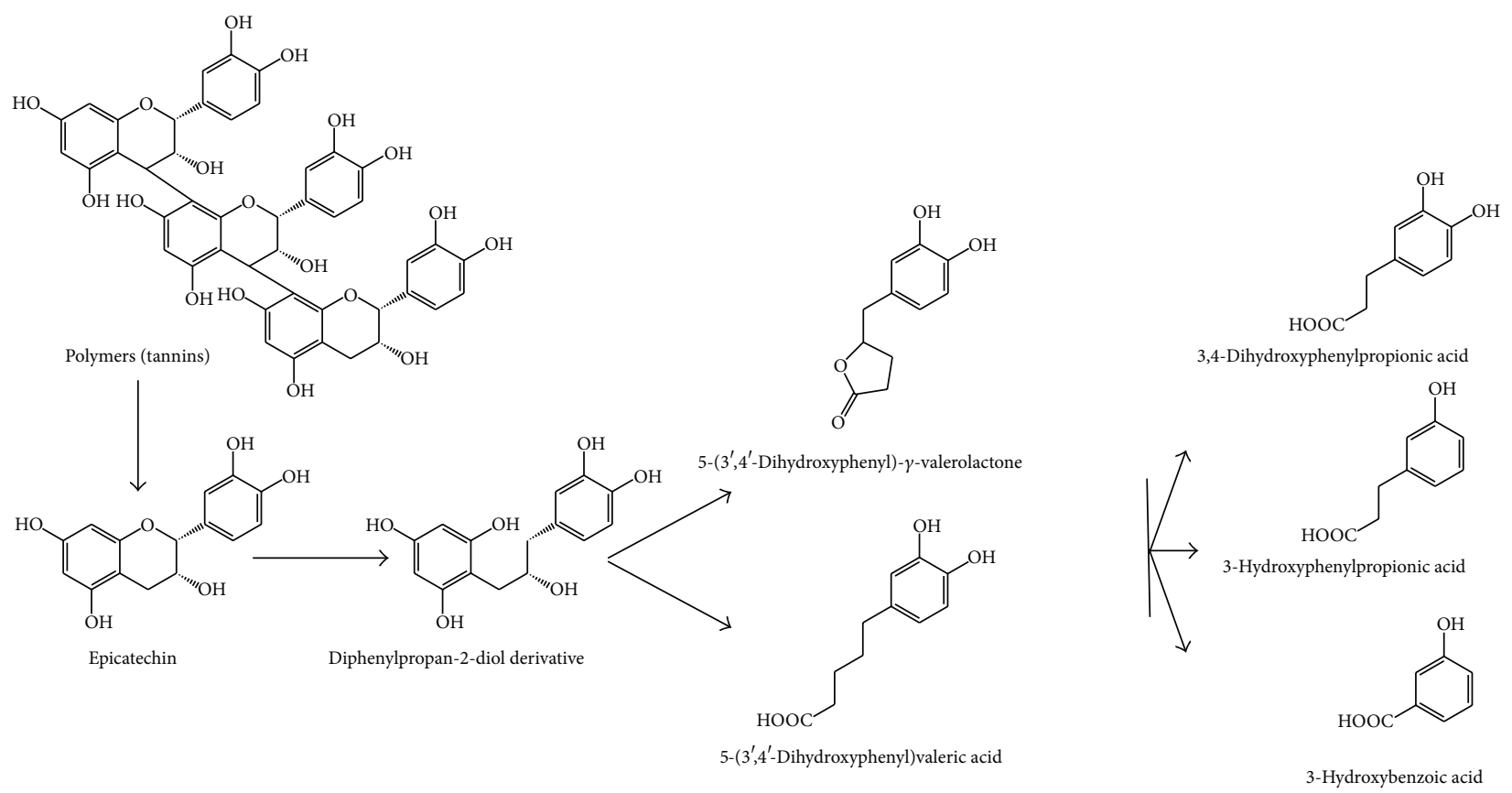

FIgURE 6: Colonic degradation of epicatechin tannins, as an example of flavan-3-ol polymers.

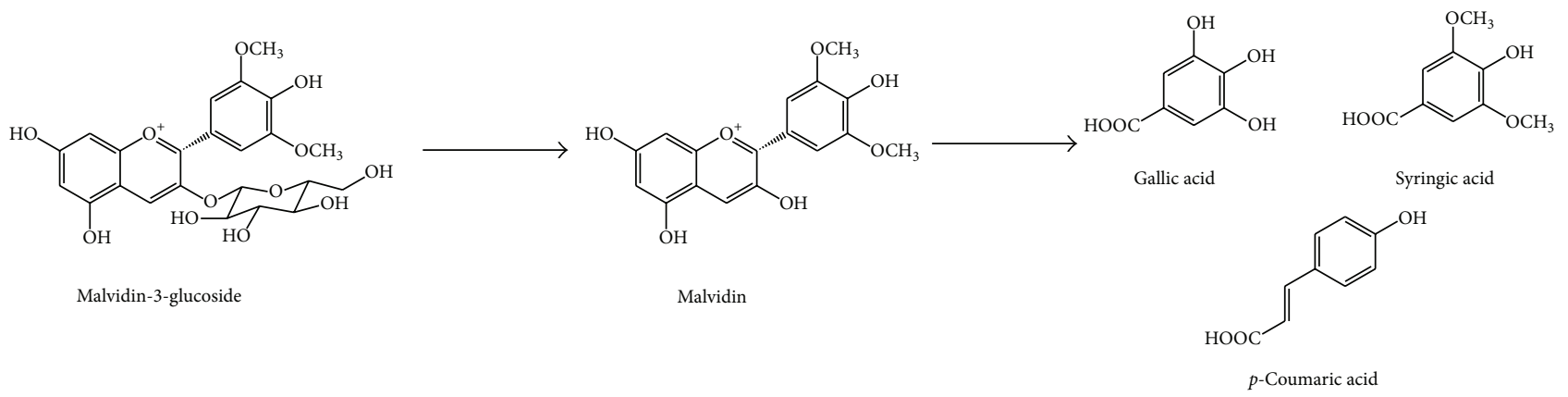

FIGURE 7: Colonic degradation of malvidin-3-glucoside, as an example of anthocyanin.

by the oxidized compounds, possibly through reaction with sulfhydryl groups or through more nonspecific interactions with proteins often leading to inactivation of the membrane protein and loss of function. Probable targets in the microbial cell are surface-exposed adhesions, cell wall polypeptides, and membrane-bound enzymes. Anthocyanidins may also render substrates unavailable to microorganisms, as some oligoelements [128, 129].

Many studies have shown the antimicrobial activities of the crude extract, fractions, and pure anthocyanidins from different berries. In bilberries (Vaccinium myrtillus), anthocyanins comprise $90 \%$ of the phenolic compounds. Extracts from bilberry and blueberry (Vaccinium corymbosum) showed inhibitory effects on the growth of Grampositive bacteria (Listeria monocytogenes, S. aureus, Bacillus subtilis, and Enterococcus faecalis) and Gram-negative ones (Citrobacter freundii, E. coli, Pseudomonas aeruginosa, and
Salmonella enterica ser. Typhimurium). However yeasts are resistant to these berry extracts [130].

Cyanidin-3-O-glucoside $(\mathrm{C} 3 \mathrm{G})$ inhibits the secretion of both VacA and CagA, two key virulence factors of $H$. pylori $[131,132]$. C3G downregulates VacA secretion in $H$. pylori via inhibition of SecA expression (a protein involved in translocation of bacterial proteins out of the bacterial plasma membrane), causing a decrease in apoptosis in $H$. pyloriinfected cells [132].

Cyanidin-3-sambubioside, a natural anthocyanin derived from black elderberry extract, binds to influenza virus neuraminidase within the 430-cavity, acting as a potent inhibitor of sialidase activity. This natural anthocyanin binds in the vicinity of neuraminidase residues 356-364 and 395-432, shielding proteases from releasing these peptide segments from the active site. This binding mode has not been seen with other influenza neuraminidase inhibitors so that the 
compound and its derivatives definitely offer the potential for the development of a new class of antivirals against influenza [133].

2.5. Isoflavones. Almost all isoflavones (daidzein, genistein, and formononetin) exist as glucosides and therefore are not absorbed across enterocytes due to their high polarity and molecular weight. These flavonoids are present almost exclusively in plants from the Fabaceae family (soy, lentils, beans, and chickpeas). Their bioavailability requires therefore conversion of glucosides into the bioactive aglycones via the action of intestinal $\beta$-glucosidases from small intestine bacteria (Lactobacillus, Bifidobacterium). Then, these aglycones are uptaken to the peripheral circulation [134].

One of the most active isoflavones, daidzein, is metabolized in two different ways depending on subjects and their gut microbiota. Some subjects produce $(S)$-equol via dihydrodaidzein and tetrahydrodaidzein (resulting from the activities of Streptococcus intermedius, B. ovatus, Ruminococcus productus, Lactobacillus mucosae EPI2, E. faecium EPI1, Veillonella spp., Eggerthella sp. Julong732, and Finegoldia magna EPI3) [31-33] (Figure 8). However others produce O-desmethylangolensin (O-DMA) via $2^{\prime}$-dehydro-Odemethylangolensin (generated by Clostridium spp.) [34] (Figure 8) (Table 1). Therefore, there are two groups of subjects, $(S)$-equol producers and nonproducers. The inability to produce $(S)$-equol is a consequence of the lack of specific components in the intestinal microbiota, as the species described before. $(S)$-equol shows high antioxidant activity due to its nonplanar structure, which enables it to penetrate more easily into the interior of the cell membrane, preventing oxidative damage in situ. Also its estrogenic activity on mammal cells is higher in comparison with other phytoestrogens. This compound binds to estrogen receptor in mammal cells, downregulating its activity. This may have potential application in breast and prostate cancer therapy and prevention [135-137]. In addition to $(S)$-equol and $\mathrm{O}$ DMA, other less active microbial metabolites of daidzein have been reported [138].

Microbial metabolism of isoflavone genistein is different from that of daidzein. Genistein is reduced to dihydrogenistein, which is further metabolized to $6^{\prime}$-hydroxy-Odesmethylangolensin [35].

Other less common isoflavones found in red clover are formononetin and biochanin $\mathrm{A}$, which are converted in a similar way to microbial metabolites. Formononetin is rapidly converted via daidzein to O-DMA and $(S)$-equol. Biochanin $\mathrm{A}$ is metabolized via genistein to $6^{\prime}$-hydroxy-Odesmethylangolensin [36]. Then, all these isoflavone aglycones are further transformed by C-ring cleavage and dehydroxylation reactions in the colon.

Apart from their estrogenic activity, studies with respect to the antimicrobial activity of isoflavones have been described, as, for example, inhibition of $S$. aureus MRSA strains at concentrations over $128 \mu \mathrm{g} / \mathrm{mL}$ [139-141]. These activities are thought to be due to inhibition of bacterial topoisomerase IV [142].
2.6. Flavones. These flavonoids (luteolin, apigenin) share the 2-phenylchromen-4-one (2-phenyl-1-benzopyran-4-one) backbone. They are present in food as cereals, parsley, thyme, celery, and citrus fruits. Once the corresponding glucosides have been hydrolyzed at intestinal level, unabsorbed aglycons are further metabolized by colon microbiota (C. orbiscindens, Enterococcus avium), breaking down their C-ring towards phloretin chalcone, 3-(3,4-dihydroxyphenyl)-propionic acid, 3-(4-hydroxyphenyl)-propionic acid, 3-(3-hydroxyphenyl)propionic acid, and 4-hydroxycinnamic acid, which are absorbed and excreted by urine [37] (Table 1).

Luteolin and its glycosides have been isolated from plants used in traditional medicine to treat a wide range of diseases. Tests for antiherpetic substances from crude methanol leaf extract of Avicenna marina have shown that the most active fraction isolated and analyzed contained luteolin 7-Omethylether-3'-O-beta-D-glucoside (LMEG). LMEG exerts an inhibitory effect on the early stage of herpes simplex virus 2 (HSV-2) infection probably inhibiting HSV attachment to the cell membrane and its entry into the cell [143]. Among several compounds isolated from Swertia macrosperma, luteolin was the most active compound in inhibiting the secretion of hepatitis B virus surface antigen (HBsAg) and hepatitis $B$ virus e-antigen ( $\mathrm{HBeAg}$ ) with IC50 values of 0.02 and $0.02 \mathrm{mM}$, respectively [144].

Regarding the antibacterial effects, luteolin is active against B. subtilis, S. aureus, P. fluorescens and E. coli $[145,146]$. The major constituents isolated from the methanol extract of Daucus carota (carrot) seeds are luteolin, luteolin-3'-Obeta-D-glucopyranoside, and luteolin- $4^{\prime}$-O-beta-D-glucopyranoside. Both luteolin and its $4^{\prime}$-O-glucoside demonstrated bactericidal activity against $S$. aureus and E. coli $(\mathrm{MIC}=$ $5.0 \times 10^{-2}$ and $1.0 \times 10^{-1} \mathrm{mg} / \mathrm{mL}$, resp.) [147]. Luteolin shows antibacterial and synergistic activity against amoxicillinresistant $E$. coli, acting via three mechanisms: inhibition of proteins and peptidoglycan synthesis, inhibition of extendedspectrum $\beta$-lactamases, and alteration of outer and inner membrane permeability [148].

Luteolin and its glycosides also show antiparasitic activity. Luteolin present in extract from Melampyrum arvense was the most active compound against Trypanosoma brucei ssp. rhodesiense and L. donovani (IC(50) values 3.8 and $3.0 \mu \mathrm{g} / \mathrm{mL}$ ) [149]. Luteolin-7-O- $\beta$-glucopyranoside displayed the best antiplasmodial activity against $P$. falciparum (IC(50) value $2.9 \mu \mathrm{g} / \mathrm{mL}$ ) [149].

2.7. Hydrolyzable Tannins. Hydrolyzable tannins are a class of polyphenols that include gallotannins and ellagitannins (ETs) (Figure 4). These compounds are present in fruits like raspberry, cranberries, strawberries, walnuts, grapes, and pomegranate. A main difference between these two groups is that, upon gut microbial hydrolysis, gallotannins yield glucose and gallic acid, whereas ellagitannins undergo lactonization producing ellagic acid (Figure 4).

Ellagic acid is largely metabolized by the colon microbiota, giving rise to urolithin A (3,8-dihydroxy-6H-dibenzopyran-6-one) and its monohydroxylated analog known as urolithin $B[150,151]$. There is a large interindividual variation 


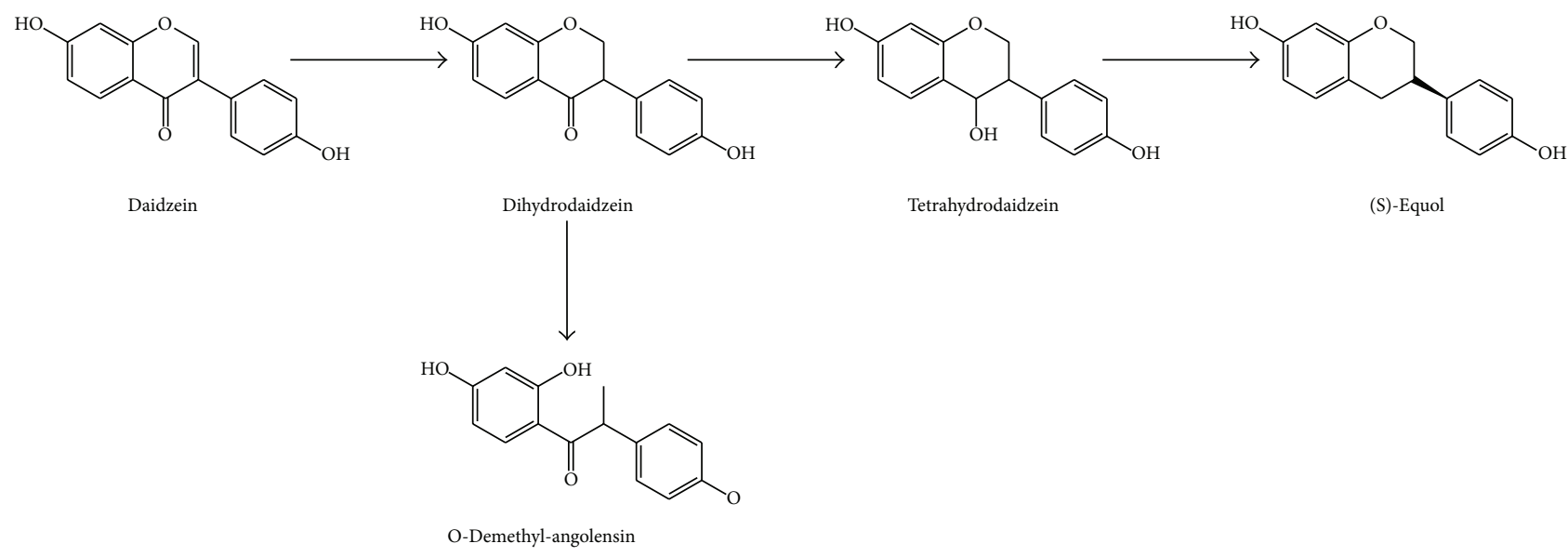

Figure 8: Colonic formation of $(S)$-equol and O-demethylangolensin from the isoflavone daidzein.

in the timing, quantity, and types of urolithins excreted in urine by humans. These variations are due to the variations in colonic microbiota composition $[152,153]$. Despite all the data indicating the microbial origin of urolithins, no specific bacteria for urolithin biosynthesis have been yet identified. One bacterium (Butyrivibrio spp.), responsible for ellagitannins modification, has been identified in rumen fluids [38] (Table 2).

Ellagic acid from Phyllanthus urinaria, a domestic plant grown in Korea, shows specific antiviral activity against hepatitis $B$ virus (HBV), by inhibiting $\mathrm{HBeAg}$ secretion, in HBVinfected cells [154]. ETs are potent antiviral agents against herpes simplex virus, specially eugenin extracted from Geum japonicum and Syzygium aromaticum [155]. Pomegranate (Punica granatum) polyphenols suppress the replicative ability of influenza A virus in host cells. Punicalagin is the most effective anti-influenza component in this extract, blocking replication of influenza virus RNA and inhibiting agglutination of chicken red blood cells by the virus $[156,157]$. Geranin and corilagin are two ETs extracted from Phyllanthus amarus restrained by $50 \%$ the interaction of glycoprotein 120 of HIV-1 at concentrations from 2.65 to $0.48 \mu \mathrm{g} / \mathrm{mL}$ on the primary cellular receptor CD4 [158].

Plant extracts from Pteleopsis hylodendron, containing mainly ellagic acid, are active against Klebsiella pneumoniae, Bacillus cereus, E. coli, and S. typhi [159]. ETs present in pomegranate peel are effective also in inhibiting $S$. aureus, Salmonella, L. monocytogenes, and E. coli [160-164]. Ellagic acid extract from pomegranate inhibits formation of biofilms by $S$. aureus, methicillin resistant $S$. aureus (MRSA), and $E$. coli. [79].

Punicalagin, punicalin, gallagic, and ellagic acids show antifungal properties against Candida albicans, C. neoformans, and Aspergillus fumigatus [165]. Apart from inhibiting biofilm formation, pomegranate extracts disrupt preformed biofilms and inhibited germ tube formation in C. albicans [164].

In vitro antimalarial activity of ellagic acid has been reported, with high in vitro activity against all $P$. falciparum strains regardless of their levels of chloroquine and mefloquine resistance $(50 \%$ inhibitory concentrations ranging from 105 to $330 \mathrm{nM}$ ) [166]. This antimalarial activity takes place at the mature trophozoite and young schizont stages, corresponding to protein and nucleic acid synthesis. Ellagic acid potentiates also the activity of current antimalarial drugs such as chloroquine, mefloquine, artesunate, and atovaquone [167].

2.8. Lignans. Lignans include a number of diphenolic compounds with a 1,4-diarylbutane structure such as secoisolariciresinol, matairesinol, pinoresinol, lariciresinol, isolariciresinol, and syringaresinol. They are common in seeds as flax and cereals and in fruits as strawberries and apricots.

Lignan metabolism involves both mammalian (glucuronidation and to a lesser degree sulfation) and gut microbial processes [39]. Biological activity of lignans is related to the activation of these compounds by Bacteroides and Clostridium species (in the gut microbiota) to enterolactone and enterodiol (Figure 9), which are phytoestrogens in mammals [40]. This transformation of lignans into phytoestrogens is carried out after demethylation and dehydroxylation reactions (carried out by Peptostreptococcus and Eubacterium species), which increase the structural diversity of enterolignan derivatives in blood circulation (Table 2) [41] (Figure 9). Thus, enterolactone conversion from enterodiol is a complex phenomenon, involving several precursors, different intermediary metabolites, and diverse conjugation patterns. Production of enterolactone was compared to that of enterodiol and a ratio of enterolactone- and enterodiolconverting bacteria of 1:2000 was observed, indicating that enterodiol-producing bacteria are dominant in human gut [42] (Table 2).

2.9. Chlorogenic Acids. Chlorogenic acids are a group of compounds comprising hydroxycinnamates (such as caffeic acid, ferulic acid, and $p$-coumaric acid) (Figure 1), linked to a quinic acid to form a range of conjugated structures 
TABLE 2: Main metabolites derived from nonflavonoids and identified bacteria involved in their transformation.

\begin{tabular}{|c|c|c|c|}
\hline Precursors & Main identified metabolites & Bacteria & References \\
\hline Ellagitannins & Urolithins & Butyrivibrio spp. & [38] \\
\hline Lignans & $\begin{array}{l}\text { Enterodiol } \\
\text { Enterolactone }\end{array}$ & $\begin{array}{l}\text { Bacteroides distasonis, Bacteroides fragilis, Bacteroides } \\
\text { ovatus, Clostridium cocleatum, Butyribacterium } \\
\text { methylotrophicum, Eubacterium callanderi, } \\
\text { Eubacterium limosum, Peptostreptococcus } \\
\text { productus, Clostridium scindens, Eggerthella lenta }\end{array}$ & {$[39-42]$} \\
\hline Hydroxycinnamates & $\begin{array}{l}\text { 3-Hydroxyphenylpropionic acid } \\
\text { Benzoic acid } \\
\text { 3-(4-Hydroxyphenyl)propionic acid } \\
\text { Vanillin }\end{array}$ & $\begin{array}{l}\text { Escherichia coli, Bifidobacterium lactis, Lactobacillus } \\
\text { gasseri }\end{array}$ & {$[43-45]$} \\
\hline
\end{tabular}

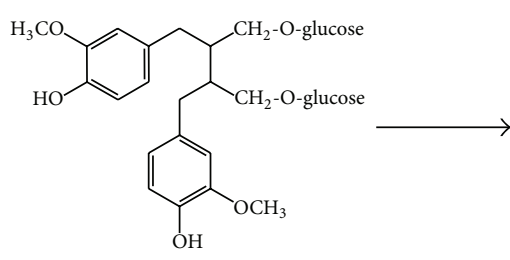

Secoisolariciresinol diglucoside (lignan)

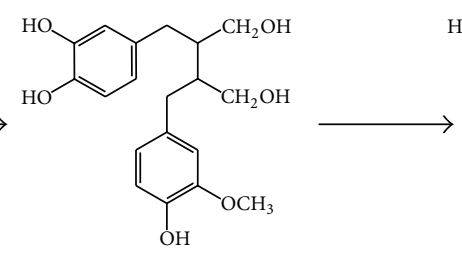

OH<smiles>OCC(CO)Cc1cccc(O)c1</smiles><smiles>O=C1OCC(Cc2cccc(O)c2)C1Cc1cccc(O)c1</smiles>

Enterolactone

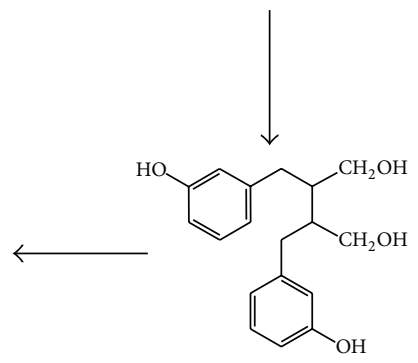

Enterodiol

FIGURE 9: Colonic formation of enterodiol and enterolactone from the lignan secoisolariciresinol diglucoside.

known, respectively, as caffeoylquinic acids, feruloylquinic acids, and $p$-coumaroylquinic acids. They are abundant in fruits as peaches and plums and in some seeds, like coffee.

Literature describing the bioavailability of chlorogenic acids is scarce and contradictory. However, several microbial metabolites have been identified. The main microbial metabolites of caffeic acid are 3-hydroxyphenylpropionic acid and benzoic acid, generated by the action of E. coli, B. lactis, and Lactobacillus gasseri (Table 2). The first one is formed by de-esterification, reduction of a double bond, and dehydroxylation. Furthermore, $\beta$-oxidation shortens the side-chain and forms benzoic acid in small degree. Both metabolites are also obtained from chlorogenic acid [43]. The most frequent metabolites from ferulic acid produced by colonic microbiota are vanillin and 3-(4-hydroxyphenyl)propionic acid $[44,45]$.

The antimicrobial activity of 22 polyphenols, including gallic acid, was investigated against 26 bacterial species. It was found that a structure-activity relationship between the strongest antibacterial activity for those polyphenols and a higher number of pyrogallol rings in their structure [168]. As gallic acid has one of those rings, its antibacterial activity was classified by these authors as moderate. The role of gallic acid is also of practical interest in the prevention of formation of biofilms by different bacteria. When biofilms formed by E. coli, $P$. aeruginosa, S. aureus, and L. monocytogenes were studied, a reduction in biofilm activity $>70 \%$ for all the biofilms tested was found [169]. Gallic acid also inhibits bacterial growth of Streptococcus mutants and the biofilm formation in vitro and also influences the adhesion properties of $S$. aureus [170].

Experimental evidences regarding the antiviral activity of gallic acid have been published as the inhibition in human rhinoviruses (HRVs), replication and reduction of HRVinduced cytopathic effect in vitro, and antienterovirus 71 activity [171] were found. The same positive results of gallic acid against herpes simplex virus type-2 were previously mentioned [172].

Gallic acid purified from Terminalia nigrovenulosa bark has shown strong antifungal activity against Fusarium solani and strong nematicidal activity against Meloidogyne incognita $[173,174]$.

\section{Conclusions}

Most polyphenol nutraceuticals from plant origin must undergo intestinal transformations, by microbiota and enterocyte enzymes, in order to be absorbed at enterocyte and 
colonocyte levels. This gives rise to diverse beneficial effects in the consumer, including a vast array of protective effects against viruses, bacteria, and protozoan parasites. These enzymatic transformations include elimination of glycosidic tailoring by gut microbiota of diverse genera (Lactobacillus, Eubacterium, and Bifidobacterium), as well as further transformations in these aglycones' level, giving rise to more stable bioactive compounds that are incorporated into the blood stream, as a vast array of benzoic acids, phenolic acids, urolithins, and the phytoestrogens $(S)$-equol, enterodiol, and enterolactone. In most cases, a complex network of different intestinal microbiota species is necessary for full biotransformation, whereas earlier and simple reactions as deglycosylation can be carried out individually by specific gut strains. The individual variability, at consumer level, with respect to richness, and biodiversity of own intestinal microbiota taxa are key determinants regarding the ability of a person to get the most fully bioactive derivatives from ingested polyphenols. Final absorbed bioactive derivatives have shown antimicrobial properties against viruses (as HBV), Grampositive bacteria (as S. aureus, L. monocytogenes), and Gramnegative bacteria ( $S$. enterica, $P$. aeruginosa), but also against eukaryote species as fungi (Candida spp., T. mentagrophytes) or protozoans (T. cruzi, P. falciparum). Therefore, consumption of food with high levels of polyphenols, together with having appropriate gut microbiota diversity, is extremely important, in order to help in the fight against infectious diseases. Fermented dairy foods, as well as other ones with high levels of beneficial microorganisms, can therefore contribute to maintaining this appropriate gut microbiota diversity, facilitating intestinal production of bioactive metabolites from dietary polyphenols, as well as their absorption and bioavailability.

\section{Conflict of Interests}

The authors declare that there is no conflict of interests regarding the publication of this paper.

\section{Acknowledgments}

Authors wish to thank IUOPA (Instituto Universitario de Oncología del Principado de Asturias) and MINECO (Spanish Ministry of Economy and Competitiveness, Grant AGL2010-20622) for financial support to Laura Marín.

\section{References}

[1] G. Agati, C. Brunetti, M. Di Ferdinando, F. Ferrini, S. Pollastri, and M. Tattini, "Functional roles of flavonoids in photoprotection: new evidence, lessons from the past," Plant Physiology and Biochemistry, vol. 72, pp. 35-45, 2013.

[2] M. Mori, K. Yoshida, Y. Ishigaki et al., "UV-B protective effect of a polyacylated anthocyanin, HBA, in flower petals of the blue morning glory, Ipomoea tricolor cv. Heavenly Blue," Bioorganic and Medicinal Chemistry, vol. 13, no. 6, pp. 2015-2020, 2005.

[3] A. Sugiyama, N. Shitan, and K. Yazaki, "Involvement of a soybean ATP-binding cassette-type transporter in the secretion of genistein, a signal flavonoid in legume-Rhizobium symbiosis," Plant Physiology, vol. 144, no. 4, pp. 2000-2008, 2007.
[4] O. R. Gottlieb, "The role of oxygen in phytochemical evolution towards diversity," Phytochemistry, vol. 28, pp. 2545-2558, 1989.

[5] T. Vogt, "Phenylpropanoid biosynthesis," Molecular Plant, vol. 3, no. 1, pp. 2-20, 2010.

[6] A. Crozier, I. B. Jaganath, and M. N. Clifford, "Dietary phenolics: chemistry, bioavailability and effects on health," Natural Product Reports, vol. 26, no. 8, pp. 1001-1043, 2009.

[7] K. Marinova, K. Kleinschmidt, G. Weissenböck, and M. Klein, "Flavonoid biosynthesis in barley primary leaves requires the presence of the vacuole and controls the activity of vacuolar flavonoid transport," Plant Physiology, vol. 144, no. 1, pp. 432444, 2007.

[8] L. Pourcel, N. G. Irani, Y. Lu, K. Riedl, S. Schwartz, and E. Grotewold, "The formation of anthocyanic vacuolar inclusions in arabidopsis thaliana and implications for the sequestration of anthocyanin pigments," Molecular Plant, vol. 3, no. 1, pp. 78-90, 2010.

[9] T. Raab, D. Barron, F. Arce Vera, V. Crespy, M. Oliveira, and G. Williamson, "Catechin glucosides: occurrence, synthesis, and stability," Journal of Agricultural and Food Chemistry, vol. 58, no. 4, pp. 2138-2149, 2010.

[10] P. C. Hollman, M. N. Bijsman, Y. van Gameren, E. P. Cnossen, J. H. de Vries, and M. B. Katan, "The sugar moiety is a major determinant of the absorption of dietary flavonoid glycosides in man," Free Radical Research, vol. 31, no. 6, pp. 569-573, 1999.

[11] U. Lewandowska, K. Szewczyk, E. Hrabec, A. Janecka, and S. Gorlach, "Overview of metabolism and bioavailability enhancement of polyphenols," Journal of Agricultural and Food Chemistry, vol. 61, no. 50, pp. 12183-12199, 2013.

[12] M. D’Archivio, C. Filesi, R. Varì, B. Scazzocchio, and R. Masella, "Bioavailability of the polyphenols: Status and controversies," International Journal of Molecular Sciences, vol. 11, no. 4, pp. 1321-1342, 2010.

[13] J. B. Harborne and C. A. Williams, "Advances in flavonoid research since 1992," Phytochemistry, vol. 55, no. 6, pp. 481-504, 2000.

[14] A. J. Day, F. J. Cañada, J. C. Díaz et al., "Dietary flavonoid and isoflavone glycosides are hydrolysed by the lactase site of lactase phlorizin hydrolase," FEBS Letters, vol. 468, no. 2-3, pp. 166-170, 2000.

[15] A. J. Day, M. S. Dupont, S. Ridley et al., "Deglycosylation of flavonoid and isoflavonoid glycosides by human small intestine and liver $\beta$-glucosidase activity," FEBS Letters, vol. 436, no. 1, pp. 71-75, 1998.

[16] J. M. Gee, M. S. DuPont, A. J. Day, G. W. Plumb, G. Williamson, and I. T. Johnson, "Intestinal transport of quercetin glycosides in rats involves both deglycosylation and interaction with the hexose transport pathway," Journal of Nutrition, vol. 130, no. 11, pp. 2765-2771, 2000.

[17] S. H. Bang, Y. J. Hyun, J. Shim, S. W. Hong, and D. H. Kim, "Metabolism of rutin and poncirin by human intestinal microbiota and cloning of their metabolizing $\alpha$-L-rhamnosidase from Bifidobacterium dentium," Journal of Microbiology and Biotechnology, vol. 24, no. 3, 2014.

[18] K. Nakagawa, S. Okuda, and T. Miyazawa, "Dose-dependent incorporation of tea catechins, (-)-epigallocatechin-3-gallate and (-)-epigallocatechin, into human plasma," Bioscience, Biotechnology and Biochemistry, vol. 61, no. 12, pp. 1981-1985, 1997.

[19] S. Deprez, I. Mila, J.-F. Huneau, D. Tome, and A. Scalbert, "Transport of proanthocyanidin dimer, trimer, and polymer 
across monolayers of human intestinal epithelial Caco-2 cells," Antioxidants and Redox Signaling, vol. 3, no. 6, pp. 957-967, 2001.

[20] J. Winter, L. H. Moore, V. R. Dowell Jr., and V. D. Bokkenheuser, "C-ring cleavage of flavonoids by human intestinal bacteria," Applied and Environmental Microbiology, vol. 55, no. 5, pp. 1203-1208, 1989.

[21] A. R. Rechner, M. A. Smith, G. Kuhnle et al., "Colonic metabolism of dietary polyphenols: influence of structure on microbial fermentation products," Free Radical Biology and Medicine, vol. 36, no. 2, pp. 212-225, 2004.

[22] L. R. Krumholz and M. P. Bryant, "Eubacterium oxidoreducens sp. nov. requiring $\mathrm{H}_{2}$ or formate to degrade gallate, pyrogallol, phloroglucinol and quercetin," Archives of Microbiology, vol. 144, no. 1, pp. 8-14, 1986.

[23] H. Schneider, R. Simmering, L. Hartmann, H. Pforte, and M. Blaut, "Degradation of quercetin-3-glucoside in gnotobiotic rats, associated with human intestinal bacteria," Journal of Applied Microbiology, vol. 89, no. 6, pp. 1027-1037, 2000.

[24] C. Manach, G. Williamson, C. Morand, A. Scalbert, and C. Rémésy, "Bioavailability and bioefficacy of polyphenols in humans. I. Review of 97 bioavailability studies," The American Journal of Clinical Nutrition, vol. 81, supplement 1, pp. 230S242S, 2005.

[25] M. Monagas, M. Urpi-Sarda, F. Sánchez-Patán et al., "Insights into the metabolism and microbial biotransformation of dietary flavan-3-ols and the bioactivity of their metabolites," Food and Function, vol. 1, no. 3, pp. 233-253, 2010.

[26] X. Tzounis, J. Vulevic, G. G. C. Kuhnle et al., "Flavanol monomer-induced changes to the human faecal microflora," British Journal of Nutrition, vol. 99, no. 4, pp. 782-792, 2008.

[27] H. Schneider and M. Blaut, "Anaerobic degradation of flavonoids by Eubacterium ramulus," Archives of Microbiology, vol. 173, no. 1, pp. 71-75, 2000.

[28] J. Yamakoshi, S. Tokutake, M. Kikuchi, Y. Kubota, H. Konishi, and T. Mitsuoka, "Effect of proanthocyanidin-rich extract from grape seeds on human fecal flora and fecal odor," Microbial Ecology in Health and Disease, vol. 13, no. 1, pp. 25-31, 2001.

[29] B. Miladinović, M. Kostić, K. Šavikin et al., "Chemical profile and antioxidative and antimicrobial activity of juices and extracts of 4 black currants varieties (Ribes nigrum L.)," Journal of Food Science, vol. 79, pp. C301-C309, 2014.

[30] D. Burdulis, A. Šarkinas, I. Jasutiené, E. Stackevičiene, L. Nikolajevas, and V. Janulis, "Comparative study of anthocyanin composition, antimicrobial and antioxidant activity in bilberry (Vaccinium myrtillus L.) and blueberry (Vaccinium corymbosum L.) fruits," Acta Poloniae Pharmaceutica-Drug Research, vol. 66, no. 4, pp. 399-408, 2009.

[31] K. Minamida, M. Tanaka, A. Abe et al., "Production of equol from daidzein by gram-positive rod-shaped bacterium isolated from rat intestine," Journal of Bioscience and Bioengineering, vol. 102, no. 3, pp. 247-250, 2006.

[32] H. Wiseman, K. Casey, E. A. Bowey et al., "Influence of $10 \mathrm{wk}$ of soy consumption on plasma concentrations and excretion of isoflavonoids and on gut microflora metabolism in healthy adults," American Journal of Clinical Nutrition, vol. 80, no. 3, pp. 692-699, 2004.

[33] K. Decroos, S. Vanhemmens, S. Cattoir, N. Boon, and W. Verstraete, "Isolation and characterisation of an equol-producing mixed microbial culture from a human faecal sample and its activity under gastrointestinal conditions," Archives of Microbiology, vol. 183, no. 1, pp. 45-55, 2005.
[34] H.-G. Hur, R. D. Beger, T. M. Heinze et al., "Isolation of an anaerobic intestinal bacterium capable of cleaving the C-ring of the isoflavonoid daidzein," Archives of Microbiology, vol. 178, no. 1, pp. 8-12, 2002.

[35] N. G. Coldham, C. Darby, M. Hows, L. J. King, A.-Q. Zhang, and M. J. Sauer, "Comparative metabolism of genistin by human and rat gut microflora: detection and identification of the endproducts of metabolism," Xenobiotica, vol. 32, no. 1, pp. 45-62, 2002.

[36] S.-M. Heinonen, K. Wähälä, and H. Adlercreutz, "Identification of urinary metabolites of the red clover isoflavones formononetin and biochanin A in human subjects," Journal of Agricultural and Food Chemistry, vol. 52, no. 22, pp. 6802-6809, 2004.

[37] L. Hanske, G. Loh, S. Sczesny, M. Blaut, and A. Braune, “The bioavailability of apigenin-7-glucoside is influenced by human intestinal microbiota in rats," Journal of Nutrition, vol. 139, no. 6, pp. 1095-1102, 2009.

[38] A. A. Odenyo, R. Bishop, G. Asefa, R. Jamnadass, D. Odongo, and P. Osuji, "Characterization of tannin-tolerant bacterial isolates from East African ruminants," Anaerobe, vol. 7, no. 1, pp. 5-15, 2001.

[39] I. Rowland, M. Faughnan, L. Hoey, K. Wähälä, G. Williamson, and A. Cassidy, "Bioavailability of phyto-oestrogens," British Journal of Nutrition, vol. 89, supplement 1, pp. S45-S58, 2003.

[40] S. Heinonen, T. Nurmi, K. Liukkonen et al., "In vitro metabolism of plant lignans: new precursors of mammalian lignans enterolactone and enterodiol," Journal of Agricultural and Food Chemistry, vol. 49, no. 7, pp. 3178-3186, 2001.

[41] L.-Q. Wang, "Mammalian phytoestrogens: enterodiol and enterolactone," Journal of Chromatography B: Analytical Technologies in the Biomedical and Life Sciences, vol. 777, no. 1-2, pp. 289-309, 2002.

[42] T. Clavel, G. Henderson, C.-A. Alpert et al., "Intestinal bacterial communities that produce active estrogen-like compounds enterodiol and enterolactone in humans," Applied and Environmental Microbiology, vol. 71, no. 10, pp. 6077-6085, 2005.

[43] M.-P. Gonthier, C. Remesy, A. Scalbert et al., "Microbial metabolism of caffeic acid and its esters chlorogenic and caftaric acids by human faecal microbiota in vitro," Biomedicine \& Pharmacotherapy, vol. 60, no. 9, pp. 536-540, 2006.

[44] M. F. Andreasen, P. A. Kroon, G. Williamson, and M.-T. GarciaConesa, "Esterase activity able to hydrolyze dietary antioxidant hydroxycinnamates is distributed along the intestine of mammals," Journal of Agricultural and Food Chemistry, vol. 49, no. 11, pp. 5679-5684, 2001.

[45] D. Couteau, A. L. McCartney, G. R. Gibson, G. Williamson, and C. B. Faulds, "Isolation and characterization of human colonic bacteria able to hydrolyse chlorogenic acid," Journal of Applied Microbiology, vol. 90, no. 6, pp. 873-881, 2001.

[46] M. N. Clifford, "Chlorogenic acids and other cinnamatesnature, occurrence, dietary burden, absorption and metabolism," Journal of the Science of Food and Agriculture, vol. 80, no. 7, pp. 1033-1043, 2000.

[47] M. R. Olthof, P. C. H. Hollman, and M. B. Katan, "Chlorogenic acid and caffeic acid are absorbed in humans," Journal of Nutrition, vol. 131, no. 1, pp. 66-71, 2001.

[48] G. Borges, M. E. J. Lean, S. A. Roberts, and A. Crozier, "Bioavailability of dietary (poly)phenols: a study with ileostomists to discriminate between absorption in small and large intestine," Food \& Function, vol. 4, no. 5, pp. 754-762, 2013. 
[49] T. Erk, J. Hauser, G. Williamson et al., "Structure- and doseabsorption relationships of coffee polyphenols," BioFactors, vol. 40, no. 1, pp. 103-112, 2014.

[50] J. M. Landete, "Ellagitannins, ellagic acid and their derived metabolites: a review about source, metabolism, functions and health," Food Research International, vol. 44, no. 5, pp. 1150-1160, 2011.

[51] I. B. Jaganath, W. Mullen, C. A. Edwards, and A. Crozier, "The relative contribution of the small and large intestine to the absorption and metabolism of rutin in man," Free Radical Research, vol. 40, no. 10, pp. 1035-1046, 2006.

[52] M. V. Selma, J. C. Espín, and F. A. Tomás-Barberán, "Interaction between phenolics and gut microbiota: role in human health," Journal of Agricultural and Food Chemistry, vol. 57, no. 15, pp. 6485-6501, 2009.

[53] A. Stalmach, H. Steiling, G. Williamson, and A. Crozier, "Bioavailability of chlorogenic acids following acute ingestion of coffee by humans with an ileostomy," Archives of Biochemistry and Biophysics, vol. 501, no. 1, pp. 98-105, 2010.

[54] S. E. Nielsen, V. Breinholt, U. Justesen, C. Cornett, and L. O. Dragsted, "In vitro biotransformation of flavonoids by rat liver microsomes," Xenobiotica, vol. 28, no. 4, pp. 389-401, 1998.

[55] M.-J. Lee, P. Maliakal, L. Chen et al., "Pharmacokinetics of tea catechins after ingestion of green tea and (-)-epigallocatechin3-gallate by humans: Formation of different metabolites and individual variability," Cancer Epidemiology Biomarkers and Prevention, vol. 11, no. 10 I, pp. 1025-1032, 2002.

[56] C. Tilgmann and I. Ulmanen, "Purification methods of mammalian catechol-O-methyltransferase," Journal of Chromatography B: Biomedical Applications, vol. 684, no. 1-2, pp. 147-161, 1996.

[57] J. L. Donovan, V. Crespy, C. Manach et al., "Catechin is metabolized by both the small intestine and liver of rats," Journal of Nutrition, vol. 131, no. 6, pp. 1753-1757, 2001.

[58] C. N. Falany, "Enzymology of human cytosolic sulfotransferases," The FASEB Journal, vol. 11, no. 4, pp. 206-216, 1997.

[59] J. B. Vaidyanathan and T. Walle, "Glucuronidation and sulfation of the tea flavonoid (-)-Epicatechin by the human and rat enzymes," Drug Metabolism and Disposition, vol. 30, no. 8, pp. 897-903, 2002.

[60] V. Crespy, C. Morand, C. Besson, C. Manach, C. Démigné, and C. Rémésy, "Comparison of the intestinal absorption of quercetin, phloretin and their glucosides in rats," Journal of Nutrition, vol. 131, no. 8, pp. 2109-2114, 2001.

[61] M. Ouzzine, L. Barré, P. Netter, J. Magdalou, and S. FournelGigleux, "The human UDP-glucuronosyltransferases: structural aspects and drug glucuronidation," Drug Metabolism Reviews, vol. 35, no. 4, pp. 287-303, 2003.

[62] A.-M. Aura, "Microbial metabolism of dietary phenolic compounds in the colon," Phytochemistry Reviews, vol. 7, no. 3, pp. 407-429, 2008.

[63] F. Cardona, C. Andrés-Lacueva, S. Tulipani, F. J. Tinahones, and M. I. Queipo-Ortuño, "Benefits of polyphenols on gut microbiota and implications in human health," Journal of Nutritional Biochemistry, vol. 24, no. 8, pp. 1415-1422, 2013.

[64] J. C. Espín, M. T. García-Conesa, and F. A. Tomás-Barberán, "Nutraceuticals: facts and fiction," Phytochemistry, vol. 68, pp. 2986-3008, 2007.

[65] S. Déprez, C. Brezillon, S. Rabot et al., "Polymeric proanthocyanidins are catabolized by human colonic microflora into low-molecular-weight phenolic acids," Journal of Nutrition, vol. 130, no. 11, pp. 2733-2738, 2000.
[66] A. L. Simons, M. Renouf, S. Hendrich, and P. A. Murphy, "Human gut microbial degradation of flavonoids: structurefunction relationships," Journal of Agricultural and Food Chemistry, vol. 53, no. 10, pp. 4258-4263, 2005.

[67] J. Winter, M. R. Popoff, P. Grimont, and V. D. Bokkenheuser, "Clostridium orbiscindens sp. nov., a human intestinal bacterium capable of cleaving the flavonoid C-ring," International Journal of Systematic Bacteriology, vol. 41, no. 3, pp. 355-357, 1991.

[68] E.-M. Hein, K. Rose, G. Van't Slot, A. W. Friedrich, and H.-U. Humpf, "Deconjugation and degradation of flavonol glycosides by pig cecal microbiota characterized by fluorescence in situ hybridization (FISH)," Journal of Agricultural and Food Chemistry, vol. 56, no. 6, pp. 2281-2290, 2008.

[69] K. Ono, H. Nakane, M. Fukushima, J. C. Chermann, and F. Barré-Sinoussi, "Differential inhibitory effects of various flavonoids on the activities of reverse transcriptase and cellular DNA and RNA polymerases," European Journal of Biochemistry, vol. 190, no. 3, pp. 469-476, 1990.

[70] J. W. T. Selway, "Antiviral activity of flavones and flavans," in Plant Flavonoids in Biology and Medicine: Biochemical, Pharmacological, and Structure-Activity Relationships, V. Cody, E. Middleton, and J. B. Harborne, Eds., Alan R. Liss, New York, NY, USA, 1986.

[71] I. Mucsi, Z. Gyulai, and I. Béládi, "Combined effects of flavonoids and acyclovir against herpesviruses in cell cultures," Acta Microbiologica Hungarica, vol. 39, no. 2, pp. 137-147, 1992.

[72] K. Vijaya and S. Ananthan, “Therapeutic efficacy of medicinal plants against experimentally induced shigellosis in guinea pigs," Indian Journal of Pharmaceutical Sciences, vol. 58, no. 5, pp. 191-193, 1996.

[73] P. Palacios, G. Gutkind, R. V. D. Rondina, R. de Torres, and J. D. Coussio, "Genus baccharis. II. Antimicrobial activity of B. crispa and B. notosergila," Planta Medica, vol. 49, no. 2, article $128,1983$.

[74] O. K. Mirzoeva, R. N. Grishanin, and P. C. Calder, "Antimicrobial action of propolis and some of its components: the effects on growth, membrane potential and motility of bacteria," Microbiological Research, vol. 152, no. 3, pp. 239-246, 1997.

[75] N. S. Bakar, N. M. Zin, and D. F. Basri, "Synergy of flavone with vancomycin and oxacillin against vancomycin-intermediate Staphylococcus aureus," Pakistan Journal of Pharmaceutical Sciences, vol. 25, no. 3, pp. 633-638, 2012.

[76] E.-A. Bae, M. J. Han, and D.-H. Kim, "In vitro anti-Helicobacter pylori activity of some flavonoids and their metabolites," Planta Medica, vol. 65, no. 5, pp. 442-443, 1999.

[77] T. N. Kaul, E. Middleton Jr., and P. L. Ogra, "Antiviral effect of flavonoids on human viruses," Journal of Medical Virology, vol. 15, no. 1, pp. 71-79, 1985.

[78] H. K. Kim, W. K. Jeon, and B. S. Ko, "Flavanone glycosides from Citrus junos and their anti-influenza virus activity," Planta Medica, vol. 67, no. 6, pp. 548-549, 2001.

[79] A. S. A. Abuelsaad, I. Mohamed, G. Allam, and A. A. AlSolumani, "Antimicrobial and immunomodulating activities of hesperidin and ellagic acid against diarrheic Aeromonas hydrophila in a murine model," Life Sciences, vol. 93, no. 20, pp. 714-722, 2013.

[80] E.-A. Bae, M. J. Han, M. Lee, and D.-H. Kim, "In vitro inhibitory effect of some flavonoids on rotavirus infectivity," Biological and Pharmaceutical Bulletin, vol. 23, no. 9, pp. 1122-1124, 2000.

[81] R. K. Saha, T. Takahashi, and T. Suzuki, "Glucosyl hesperidin prevents influenza A virus replication in vitro by inhibition of 
viral sialidase," Biological and Pharmaceutical Bulletin, vol. 32, no. 7, pp. 1188-1192, 2009.

[82] J. A. del Río, P. Gómez, A. G. Baidez, M. C. Arcas, J. M. Botía, and A. Ortuño, "Changes in the levels of polymethoxyflavones and flavanones as part of the defense mechanism of Citrus sinensis (Cv. Valencia Late) fruits against Phytophthora citrophthora," Journal of Agricultural and Food Chemistry, vol. 52, no. 7, pp. 1913-1917, 2004.

[83] G. Allam and A. S. Abuelsaad, "In vitro and in vivo effects of hesperidin treatment on adult worms of Schistosoma mansoni," Journal of Helminthology, vol. 88, no. 3, pp. 362-370, 2014.

[84] A. Garg, R. A. Anderson, L. J. D. Zaneveld, and S. Garg, "Biological activity assessment of a novel contraceptive antimicrobial agent," Journal of Andrology, vol. 26, no. 3, pp. 414-421, 2005.

[85] L.-Q. Wang, M. R. Meselhy, Y. Li et al., "The heterocyclic ring fission and dehydroxylation of catechins and related compounds by Eubacterium sp. strain SDG-2, a human intestinal bacterium," Chemical and Pharmaceutical Bulletin, vol. 49, no. 12, pp. 1640-1643, 2001.

[86] K.-T. Chung, Z. Lu, and M. W. Chou, "Mechanism of inhibition of tannic acid and related compounds on the growth of intestinal bacteria," Food and Chemical Toxicology, vol. 36, no. 12, pp. 1053-1060, 1998.

[87] J. Steinmann, J. Buer, T. Pietschmann, and E. Steinmann, "Antiinfective properties of epigallocatechin-3-gallate (EGCG), a component of green tea," British Journal of Pharmacology, vol. 168, no. 5, pp. 1059-1073, 2013.

[88] S. Ciesek, T. von Hahn, C. C. Colpitts et al., "The green tea polyphenol, epigallocatechin-3-gallate, inhibits hepatitis C virus entry," Hepatology, vol. 54, no. 6, pp. 1947-1955, 2011.

[89] N. Calland, A. Albecka, S. Belouzard et al., "(-)-Epigallocatechin-3-gallate is a new inhibitor of hepatitis C virus entry," Hepatology, vol. 55, no. 3, pp. 720-729, 2012.

[90] C. Chen, H. Qiu, J. Gong et al., “(-)-Epigallocatechin-3-gallate inhibits the replication cycle of hepatitis C virus," Archives of Virology, vol. 157, no. 7, pp. 1301-1312, 2012.

[91] G. Fassina, A. Buffa, R. Benelli, O. E. Varnier, D. M. Noonan, and A. Albini, "Polyphenolic antioxidant (-)-epigallocatechin3 -gallate from green tea as a candidate anti-HIV agent," AIDS, vol. 16, no. 6, pp. 939-941, 2002.

[92] K. Kawai, N. H. Tsuno, J. Kitayama et al., "Epigallocatechin gallate, the main component of tea polyphenol, binds to CD4 and interferes with gp120 binding," Journal of Allergy and Clinical Immunology, vol. 112, no. 5, pp. 951-957, 2003.

[93] C. L. Nance, E. B. Siwak, and W. T. Shearer, "Preclinical development of the green tea catechin, epigallocatechin gallate, as an HIV-1 therapy," Journal of Allergy and Clinical Immunology, vol. 123, no. 2, pp. 459-465, 2009.

[94] S. Li, T. Hattori, and E. N. Kodama, "Epigallocatechin gallate inhibits the HIV reverse transcription step," Antiviral Chemistry and Chemotherapy, vol. 21, no. 6, pp. 239-243, 2011.

[95] F. Jiang, W. Chen, K. Yi et al., "The evaluation of catechins that contain a galloyl moiety as potential HIV-1 integrase inhibitors," Clinical Immunology, vol. 137, no. 3, pp. 347-356, 2010.

[96] M. Nakayama, K. Suzuki, M. Toda, S. Okubo, Y. Hara, and T. Shimamura, "Inhibition of the infectivity of influenza virus by tea polyphenols," Antiviral Research, vol. 21, no. 4, pp. 289-299, 1993.

[97] N. Imanishi, Y. Tuji, Y. Katada et al., "Additional inhibitory effect of tea extract on the growth of influenza A and B viruses in MDCK cells," Microbiology \& Immunology, vol. 46, no. 7, pp. 491-494, 2002.
[98] J.-M. Song, K.-H. Lee, and B.-L. Seong, "Antiviral effect of catechins in green tea on influenza virus," Antiviral Research, vol. 68, no. 2, pp. 66-74, 2005.

[99] H. Yamada, N. Takuma, T. Daimon, and Y. Hara, "Gargling with tea catechin extracts for the prevention of influenza infection in elderly nursing home residents: a prospective clinical study," Journal of Alternative and Complementary Medicine, vol. 12, no. 7, pp. 669-672, 2006.

[100] Y. Matsumoto, K. Kaihatsu, K. Nishino, M. Ogawa, N. Kato, and A. Yamaguchi, "Antibacterial and antifungal activities of new acylated derivatives of epigallocatechin gallate," Frontiers in Microbiology, vol. 3, article 53, 2012.

[101] H.-Y. Ho, M.-L. Cheng, S.-F. Weng, Y.-L. Leu, and D. T.-Y. Chiu, "Antiviral effect of epigallocatechin gallate on enterovirus 71," Journal of Agricultural and Food Chemistry, vol. 57, no. 14, pp. 6140-6147, 2009.

[102] W. He, L.-X. Li, Q.-J. Liao, C.-L. Liu, and X.-L. Chen, "Epigallocatechin gallate inhibits HBV DNA synthesis in a viral replication-inducible cell line," World Journal of Gastroenterology, vol. 17, no. 11, pp. 1507-1514, 2011.

[103] J. M. Weber, A. Ruzindana-Umunyana, L. Imbeault, and S. Sircar, "Inhibition of adenovirus infection and adenain by green tea catechins," Antiviral Research, vol. 58, no. 2, pp. 167-173, 2003.

[104] L.-K. Chang, T.-T. Wei, Y.-F. Chiu et al., "Inhibition of EpsteinBarr virus lytic cycle by (-)-epigallocatechin gallate," Biochemical and Biophysical Research Communications, vol. 301, no. 4, pp. 1062-1068, 2003.

[105] C. E. Isaacs, G. Y. Wen, W. Xu et al., "Epigallocatechin gallate inactivates clinical isolates of herpes simplex virus," Antimicrobial Agents and Chemotherapy, vol. 52, no. 3, pp. 962-970, 2008.

[106] Y. Cui, Y. J. Oh, J. Lim et al., "AFM study of the differential inhibitory effects of the green tea polyphenol (-)epigallocatechin-3-gallate (EGCG) against Gram-positive and Gram-negative bacteria," Food Microbiology, vol. 29, no. 1, pp. 80-87, 2012.

[107] A. S. Roccaro, A. R. Blanco, F. Giuliano, D. Rusciano, and V. Enea, "Epigallocatechin-gallate enhances the activity of tetracycline in staphylococci by inhibiting its efflux from bacterial cells," Antimicrobial Agents and Chemotherapy, vol. 48, no. 6, pp. 1968-1973, 2004.

[108] M. Hisano, K. Yamaguchi, Y. Inoue et al., "Inhibitory effect of catechin against the superantigen staphylococcal enterotoxin B (SEB)," Archives of Dermatological Research, vol. 295, no. 5, pp. 183-189, 2003.

[109] W.-H. Zhao, Z.-Q. Hu, S. Okubo, Y. Hara, and T. Shimamura, "Mechanism of synergy between epigallocatechin gallate and $\beta$-lactams against methicillin-resistant Staphylococcus aureus," Antimicrobial Agents and Chemotherapy, vol. 45, no. 6, pp. 17371742, 2001.

[110] Z.-Q. Hu, W.-H. Zhao, N. Asano, Y. Yoda, Y. Hara, and T. Shimamura, "Epigallocatechin gallate synergistically enhances the activity of carbapenems against methicillin-resistant Staphylococcus aureus," Antimicrobial Agents and Chemotherapy, vol. 46, no. 2, pp. 558-560, 2002.

[111] S. H. Vance, M. Tucci, and H. Benghuzzi, "Evaluation of the antimicrobial efficacy of green tea extract (EGCG) against streptococcus pyogenes in vitro," Biomedical Sciences Instrumentation, vol. 47, pp. 177-182, 2011.

[112] S. Sakanaka, L. R. Juneja, and M. Taniguchi, "Antimicrobial effects of green tea polyphenols on thermophilic spore-forming 
bacteria," Journal of Bioscience and Bioengineering, vol. 90, no. 1, pp. 81-85, 2000.

[113] Y. Yoda, Z.-Q. Hu, W.-H. Zhao, and T. Shimamura, "Different susceptibilities of Staphylococcus and Gram-negative rods to epigallocatechin gallate," Journal of Infection and Chemotherapy, vol. 10, no. 1, pp. 55-58, 2004.

[114] K. M. Lee, W. S. Kim, J. Lim, S. Nam, M. Youn, and S. W. Nam, "Antipathogenic properties of green tea polyphenol epigallocatechin gallate at concentrations below the MIC against enterohemorrhagic Escherichia coli O157:H7," Journal of Food Protection, vol. 72, no. 2, pp. 325-331, 2009.

[115] K. Matsunaga, T. W. Klein, H. Friedman, and Y. Yamamoto, "Legionella pneumophila replication in macrophages inhibited by selective immunomodulatory effects on cytokine formation by epigallocatechin gallate, a major form of tea catechins," Infection and Immunity, vol. 69, no. 6, pp. 3947-3953, 2001.

[116] S. Okubo, M. Toda, Y. Hara, and T. Shimamura, "Antifungal and fungicidal activities of tea extract and catechin against Trichophyton," Nihon Saikingaku Zasshi, vol. 46, no. 2, pp. 509514, 1991.

[117] Y. Toyoshima, S. Okubo, M. Toda, Y. Hara, and T. Shimamura, "Effect of catechin on the ultrastructure of Trichophyton mentagrophytes," Kansenshogaku Zasshi, vol. 68, no. 3, pp. 295-303, 1994.

[118] Y. Han, "Synergic anticandidal effect of epigallocatechin-Ogallate combined with amphotericin $\mathrm{B}$ in a murine model of disseminated candidiasis and its anticandidal mechanism," Biological and Pharmaceutical Bulletin, vol. 30, no. 9, pp. 16931696, 2007.

[119] M. C. Güida, M. I. Esteva, A. Camino, M. M. Flawiá, H. N. Torres, and C. Paveto, "Trypanosoma cruzi: in vitro and in vivo antiproliferative effects of epigallocatechin gallate (EGCg)," Experimental Parasitology, vol. 117, no. 2, pp. 188-194, 2007.

[120] P. R. Patil, S. Gemma, G. Campiani, and A. G. Craig, "Broad inhibition of plasmodium falciparum cytoadherence by $(+)$ epigallocatechin gallate," Malaria Journal, vol. 10, article 348, 2011.

[121] D. Tasdemir, M. Kaiser, R. Brun et al., "Antitrypanosomal and antileishmanial activities of flavonoids and their analogues: in vitro, in vivo, structure-activity relationship, and quantitative structure-activity relationship studies," Antimicrobial Agents and Chemotherapy, vol. 50, no. 4, pp. 1352-1364, 2006.

[122] J. D. F. Inacio, M. M. Canto-Cavalheiro, R. F. S. Menna-Barreto, and E. E. Almeida-Amaral, "Mitochondrial damage contribute to epigallocatechin-3-gallate induced death in Leishmania amazonensis," Experimental Parasitology, vol. 132, no. 2, pp. 151-155, 2012.

[123] M. B. G. dos Reis, L. C. Manjolin, C. D. C. Maquiaveli, O. A. Santos-Filho, and E. R. da Silva, "Inhibition of Leishmania (Leishmania) amazonensis and rat arginases by green tea EGCG, (+)-catechin and (-)-epicatechin: a comparative structural analysis of enzyme-inhibitor interactions," PLoS ONE, vol. 8, no. 11, Article ID e78387, 2013.

[124] K. Keppler and H.-U. Humpf, "Metabolism of anthocyanins and their phenolic degradation products by the intestinal microflora," Bioorganic and Medicinal Chemistry, vol. 13, no. 17, pp. 5195-5205, 2005.

[125] M. Ávila, M. Hidalgo, C. Sánchez-Moreno, C. Pelaez, T. Requena, and S. D. Pascual-Teresa, "Bioconversion of anthocyanin glycosides by Bifidobacteria and Lactobacillus," Food Research International, vol. 42, no. 10, pp. 1453-1461, 2009.
[126] M. Hidalgo, M. J. Oruna-Concha, S. Kolida et al., "Metabolism of anthocyanins by human gut microflora and their influence on gut bacterial growth," Journal of Agricultural and Food Chemistry, vol. 60, no. 15, pp. 3882-3890, 2012.

[127] A. Lacombe, V. C. H. Wu, S. Tyler, and K. Edwards, "Antimicrobial action of the American cranberry constituents; phenolics, anthocyanins, and organic acids, against Escherichia coli O157:H7," International Journal of Food Microbiology, vol. 139, no. 1-2, pp. 102-107, 2010.

[128] S. Naz, R. Siddiqi, S. Ahmad, S. A. Rasool, and S. A. Sayeed, "Antibacterial activity directed isolation of compounds from Punica granatum," Journal of Food Science, vol. 72, no. 9, pp. M341-M345, 2007.

[129] R. Puupponen-Pimiä, L. Nohynek, H.-L. Alakomi, and K.M. Oksman-Caldentey, "The action of berry phenolics against human intestinal pathogens," BioFactors, vol. 23, no. 4, pp. 243251, 2005.

[130] R. Puupponen-Pimiä, L. Nohynek, S. Hartmann-Schmidlin et al., "Berry phenolics selectively inhibit the growth of intestinal pathogens," Journal of Applied Microbiology, vol. 98, no. 4, pp. 991-1000, 2005.

[131] S.-H. Kim, M. Park, H. Woo et al., "Inhibitory effects of anthocyanins on secretion of Helicobacter pylori CagA and VacA toxins," International Journal of Medical Sciences, vol. 9, no. 10, pp. 838-842, 2012.

[132] S.-H. Kim, H. Woo, M. Park et al., "Cyanidin 3-O-glucoside reduces Helicobacter pylori VacA-induced cell death of gastric KATO III cells through inhibition of the SecA pathway," International Journal of Medical Sciences, vol. 11, no. 7, pp. 742747, 2014.

[133] K. Swaminathan, J. C. Dyason, A. Maggioni, M. von Itzstein, and K. M. Downard, "Binding of a natural anthocyanin inhibitor to influenza neuraminidase by mass spectrometry," Analytical and Bioanalytical Chemistry, vol. 405, no. 20, pp. 6563-6572, 2013.

[134] K. D. R. Setchell, N. M. Brown, L. Zimmer-Nechemias et al., "Evidence for lack of absorption of soy isoflavone glycosides in humans, supporting the crucial role of intestinal metabolism for bioavailability," American Journal of Clinical Nutrition, vol. 76, no. 2, pp. 447-453, 2002.

[135] G. E. Joannou, G. E. Kelly, A. Y. Reeder, M. Waring, and C. Nelson, "A urinary profile study of dietary phytoestrogens. The identification and mode of metabolism of new isoflavonoids," Journal of Steroid Biochemistry and Molecular Biology, vol. 54, no. 3-4, pp. 167-184, 1995.

[136] E. Bowey, H. Adlercreutz, and I. Rowland, "Metabolism of isoflavones and lignans by the gut microflora: a study in germfree and human flora associated rats," Food and Chemical Toxicology, vol. 41, no. 5, pp. 631-636, 2003.

[137] A. Ahmad, B. Biersack, Y. Li et al., "Perspectives on the role of isoflavones in prostate cancer," AAPS Journal, vol. 15, no. 4, pp. 991-1000, 2013.

[138] J.-P. Yuan, J.-H. Wang, and X. Liu, "Metabolism of dietary soy isoflavones to equol by human intestinal microfloraimplications for health," Molecular Nutrition \& Food Research, vol. 51, no. 7, pp. 765-781, 2007.

[139] T. Hatano, Y. Shintani, Y. Aga, S. Shiota, T. Tsuchiya, and T. Yoshida, "Phenolic constituents of licorice. VIII. Structures of glicophenone and glicoisoflavanone, and effects of licorice phenolics on methicillin-resistant Staphylococcus aureus," Chemical and Pharmaceutical Bulletin, vol. 48, no. 9, pp. 1286-1292, 2000. 
[140] L. Pethakamsetty, G. Seru, and L. Kandula, "Antimicrobial activity of the root extracts of T. pumila and T. tinctoria on clinical and phytopathogens," Journal of Pharmacy Research, vol. 2, pp. 1694-1696, 2009.

[141] T. Hatano, M. Kusuda, M. Tsugawa et al., Eds., Effects of Natural Polyphenols on Methicillin-Resistant Staphylococcus aureus in Relation to Their Chemical and Physical Properties in Phytochemistry Research Progress, 2008.

[142] M. Verdrengh, L. V. Collins, P. Bergin, and A. Tarkowski, "Phytoestrogen genistein as an anti-staphylococcal agent," Microbes and Infection, vol. 6, no. 1, pp. 86-92, 2004.

[143] M. Behbahani, M. S. Zadeh, and H. Mohabatkar, "Evaluation of antiherpetic activity of crude extract and fractions of Avicenna marina, in vitro," Antiviral Research, vol. 97, no. 3, pp. 376-380, 2013.

[144] H.-L. Wang, C.-A. Geng, Y.-B. Ma, X.-M. Zhang, and J.-J. Chen, "Three new secoiridoids, swermacrolactones A-C and anti-hepatitis B virus activity from Swertia macrosperma," Fitoterapia, vol. 89, no. 1, pp. 183-187, 2013.

[145] L. S. Ooi, H. Wang, Z. He, and V. E. Ooi, "Antiviral activities of purified compounds from Youngia japonica (L.) DC (Asteraceae, Compositae)," Journal of Ethnopharmacology, vol. 106, no. 2, pp. 187-191, 2006.

[146] H. I. Abd-Alla, N. S. Abu-Gabal, A. Z. Hassan, M. M. El-Safty, and N. M. M. Shalaby, "Antiviral activity of Aloe hijazensis against some haemagglutinating viruses infection and its phytoconstituents," Archives of Pharmacal Research, vol. 35, no. 8, pp. 1347-1354, 2012.

[147] Y. Kumarasamy, L. Nahar, M. Byres, A. Delazar, and S. D. Sarker, "The assessment of biological activities associated with the major constituents of the methanol extract of "wild carrot" (Daucus carota L.) seeds," Journal of Herbal Pharmacotherapy, vol. 5, no. 1, pp. 61-72, 2005.

[148] G. Eumkeb, S. Siriwong, and K. Thumanu, "Synergistic activity of luteolin and amoxicillin combination against amoxicillinresistant Escherichia coli and mode of action," Journal of Photochemistry and Photobiology B: Biology, vol. 117, pp. 247-253, 2012.

[149] H. Kirmizibekmez, I. Atay, M. Kaiser et al., "Antiprotozoal activity of Melampyrum arvense and its metabolites," Phytotherapy Research, vol. 25, no. 1, pp. 142-146, 2011.

[150] B. Cerdá, P. Periago, J. C. Espín, and F. A. Tomás-Barberán, "Identification of urolithin A as a metabolite produced by human colon microflora from ellagic acid and related compounds," Journal of Agricultural and Food Chemistry, vol. 53, no. 14, pp. 5571-5576, 2005.

[151] R. González-Barrio, C. A. Edwards, and A. Crozier, "Colonic catabolism of ellagitannins, ellagic acid, and raspberry anthocyanins: in vivo and in vitro studies," Drug Metabolism and Disposition, vol. 39, no. 9, pp. 1680-1688, 2011.

[152] R. González-Barrio, G. Borges, W. Mullen, and A. Crozier, "Bioavailability of anthocyanins and ellagitannins following consumption of raspberries by healthy humans and subjects with an ileostomy," Journal of Agricultural and Food Chemistry, vol. 58, no. 7, pp. 3933-3939, 2010.

[153] J. C. Espín, M. Larrosa, M. T. García-Conesa, and F. TomásBarberán, "Biological significance of urolithins, the gut microbial ellagic acid-derived metabolites: the evidence so far," Evidence-Based Complementary and Alternative Medicine, vol. 2013, Article ID 270418, 15 pages, 2013.

[154] M. S. Shin, E. H. Kang, and Y. I. Lee, "A flavonoid from medicinal plants blocks hepatitis B virus-e antigen secretion in
HBV-infected hepatocytes," Antiviral Research, vol. 67, no. 3, pp. 163-168, 2005.

[155] S. A. A. Jassim and M. A. Naji, "Novel antiviral agents: a medicinal plant perspective," Journal of Applied Microbiology, vol. 95, no. 3, pp. 412-427, 2003.

[156] M. Haidari, M. Ali, S. Ward Casscells III, and M. Madjid, "Pomegranate (Punica granatum) purified polyphenol extract inhibits influenza virus and has a synergistic effect with oseltamivir," Phytomedicine, vol. 16, no. 12, pp. 1127-1136, 2009.

[157] A. B. Howell and D. H. D'Souza, "The pomegranate: effects on bacteria and viruses that influence human health," EvidenceBased Complementary and Alternative Medicine, vol. 2013, Article ID 606212, 11 pages, 2013.

[158] F. Notka, G. Meier, and R. Wagner, "Concerted inhibitory activities of Phyllanthus amarus on HIV replication in vitro and ex vivo," Antiviral Research, vol. 64, no. 2, pp. 93-102, 2004.

[159] A. U. Rahman, F. N. Ngounou, M. I. Choudhary et al., "New antioxidant and antimicrobial ellagic acid derivatives from Pteleopsis hylodendron," Planta Medica, vol. 67, no. 4, pp. 335339, 2001.

[160] L. C. Braga, J. W. Shupp, C. Cummings et al., "Pomegranate extract inhibits Staphylococcus aureus growth and subsequent enterotoxin production," Journal of Ethnopharmacology, vol. 96, no. 1-2, pp. 335-339, 2005.

[161] N. S. Al-Zoreky, "Antimicrobial activity of pomegranate (Punica granatum L.) fruit peels," International Journal of Food Microbiology, vol. 134, no. 3, pp. 244-248, 2009.

[162] J.-G. Choi, O.-H. Kang, Y.-S. Lee et al., "In vitro and in vivo antibacterial activity of Punica granatum peel ethanol extract against Salmonella," Evidence-Based Complementary and Alternative Medicine, vol. 2011, Article ID 690518, 8 pages, 2011.

[163] H. Hayrapetyan, W. C. Hazeleger, and R. R. Beumer, "Inhibition of Listeria monocytogenes by pomegranate (Punica granatum) peel extract in meat paté at different temperatures," Food Control, vol. 23, no. 1, pp. 66-72, 2012.

[164] D. Bakkiyaraj, J. R. Nandhini, B. Malathy, and S. K. Pandian, "The anti-biofilm potential of pomegranate (Punica granatum L.) extract against human bacterial and fungal pathogens," Biofouling, vol. 29, no. 8, pp. 929-937, 2013.

[165] G. G. F. Nascimento, J. Locatelli, P. C. Freitas, and G. L. Silva, "Antibacterial activity of plant extracts and phytochemicals on antibiotic-resistant bacteria," Brazilian Journal of Microbiology, vol. 31, no. 4, pp. 247-256, 2000.

[166] M. Dell'Agli, S. Parapini, N. Basilico et al., "In vitro studies on the mechanism of action of two compounds with antiplasmodial activity: Ellagic acid and 3,4,5-trimethoxyphenyl (6'-Ogalloyl)- $\beta$-D-glucopyranoside," Planta Medica, vol. 69, no. 2, pp. 162-164, 2003.

[167] P. N. Soh, B. Witkowski, D. Olagnier et al., "In vitro and in vivo properties of ellagic acid in malaria treatment," Antimicrobial Agents and Chemotherapy, vol. 53, no. 3, pp. 1100-1106, 2009.

[168] T. Taguri, T. Tanaka, and I. Kouno, "Antibacterial spectrum of plant polyphenols and extracts depending upon hydroxyphenyl structure," Biological and Pharmaceutical Bulletin, vol. 29, no. 11, pp. 2226-2235, 2006.

[169] A. Borges, M. J. Saavedra, and M. Simões, “The activity of ferulic and gallic acids in biofilm prevention and control of pathogenic bacteria," Biofouling, vol. 28, no. 7, pp. 755-767, 2012.

[170] M.-S. Kang, J.-S. Oh, I.-C. Kang, S.-J. Hong, and C.-H. Choi, "Inhibitory effect of methyl gallate and gallic acid on oral bacteria," The Journal of Microbiology, vol. 46, no. 6, pp. 744750, 2008. 
[171] H. J. Choi, J. H. Song, L. R. Bhatt, and S. H. Baek, "Antihuman rhinovirus activity of gallic acid possessing antioxidant capacity," Phytotherapy Research, vol. 24, no. 9, pp. 1292-1296, 2010.

[172] J. M. Kratz, C. R. Andrighetti-Fröhner, P. C. Leal et al., "Evaluation of anti-HSV-2 activity of gallic acid and pentyl gallate," Biological and Pharmaceutical Bulletin, vol. 31, no. 5, pp. 903-907, 2008.

[173] D.-M. C. Nguyen, D.-J. Seo, V.-N. Nguyen, K.-Y. Kim, R.D. Park, and W.-J. Jung, "Nematicidal activity of gallic acid purified from Terminalia nigrovenulosa bark against the rootknot nematode Meloidogyne incognita," Nematology, vol. 15, no. 5, pp. 507-518, 2013.

[174] D.-M. Nguyen, D.-J. Seo, H.-B. Lee et al., "Antifungal activity of gallic acid purified from Terminalia nigrovenulosa bark against Fusarium solani," Microbial Pathogenesis, vol. 56, pp. 8-15, 2013. 

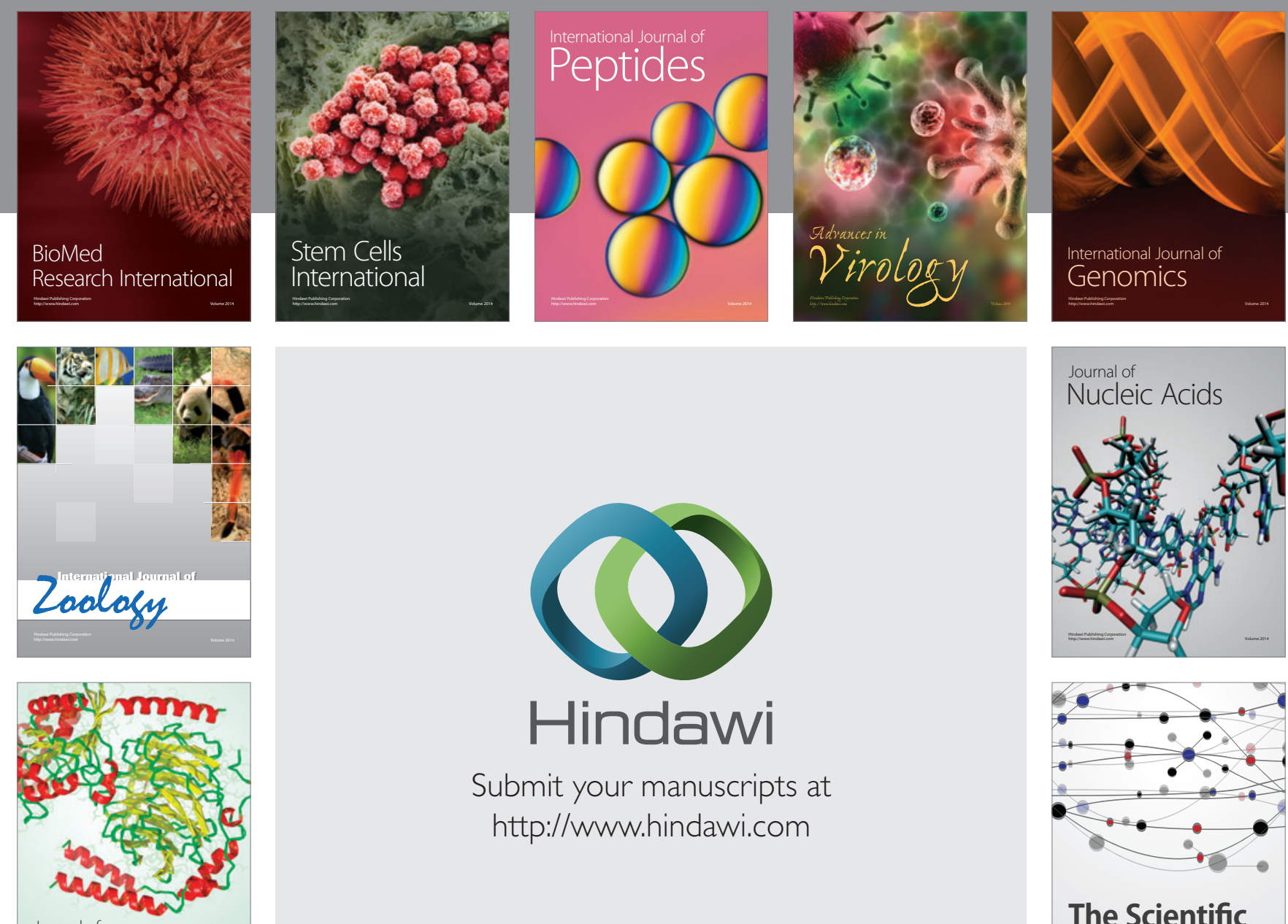

Submit your manuscripts at

http://www.hindawi.com

Journal of
Signal Transduction
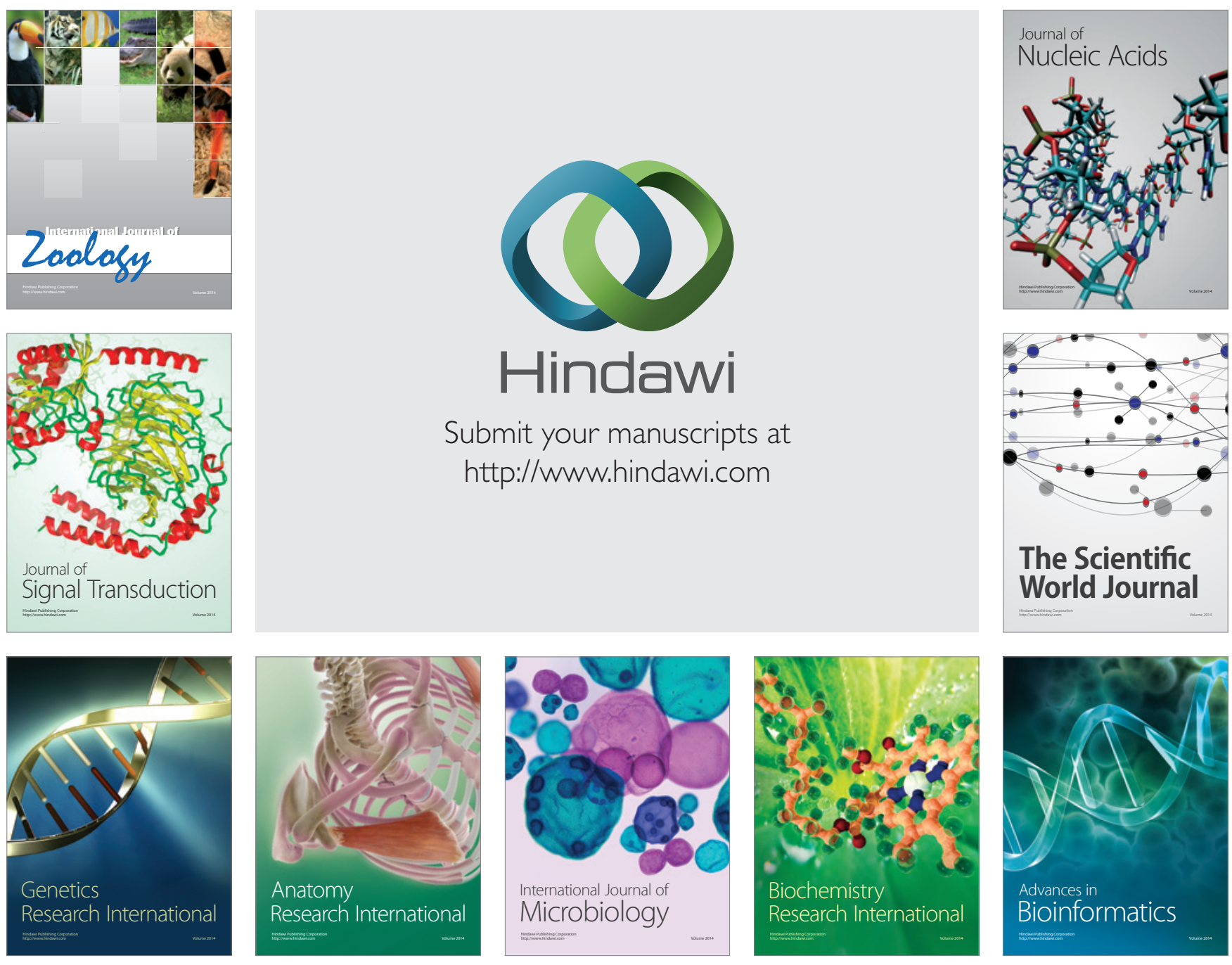

The Scientific World Journal
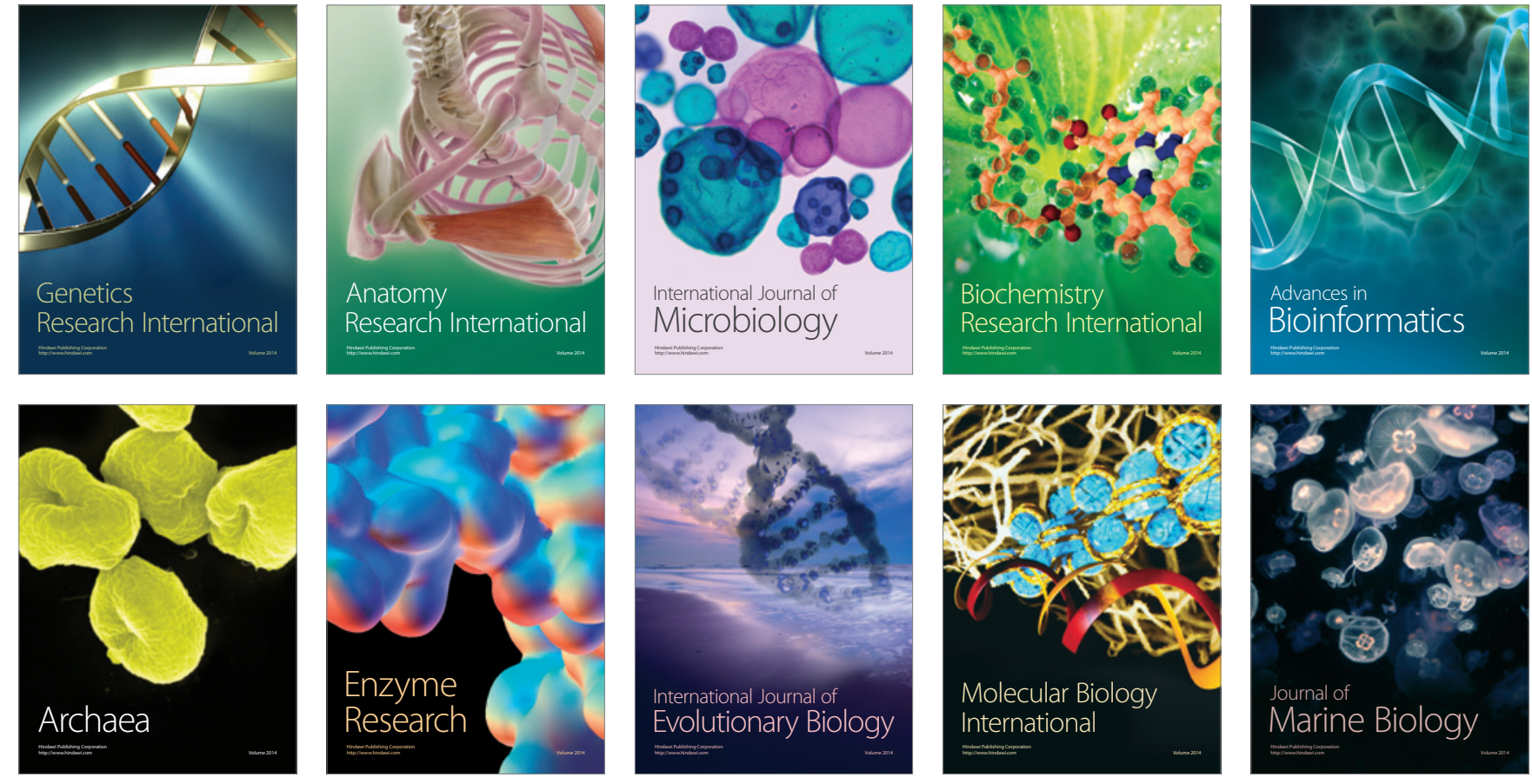